\title{
A critical perspective on interpreting amplicon sequencing data in soil ecological research
}

\author{
Lauren V. Alteio ${ }^{1}$, Joana Séneca ${ }^{1}$, Alberto Canarini ${ }^{2}$, Roey Angel $^{3}$, Ksenia Guseva ${ }^{1}$, \\ Jan Jansa ${ }^{4}$, Christina Kaiser ${ }^{1}$, Andreas Richter ${ }^{1}$, and Hannes Schmidt ${ }^{1}$ \\ ${ }^{1}$ Centre for Microbiology and Environmental Systems Science, University of Vienna, \\ Vienna, Austria \\ ${ }^{2}$ Centre for Microbiology and Environmental Systems Science, University of Vienna, \\ Austria \\ ${ }^{3}$ Soil and Water Research Infrastructure and Institute of Soil Biology, Biology Centre \\ CAS, České Budějovice, Czechia \\ ${ }^{4}$ Institute of Microbiology, Czech Academy of Sciences, Praha, Czechia
}

April 23, 2021

\section{Abstract}

2 Microbial community analysis via marker gene amplicon sequencing has become a routine method in the field of soil

research. In this perspective, we discuss technical challenges and limitations of amplicon sequencing studies in soil and

4 present statistical and experimental approaches that can help addressing the spatio-temporal complexity of soil and the

5 high diversity of organisms therein. We illustrate the impact of compositionality on the interpretation of relative abundance

6 data and discuss effects of sample replication on the statistical power in soil community analysis. Additionally, we argue

7 for the need of increased study reproducibility and data availability, as well as complementary techniques for generating

8 deeper ecological insights into microbial roles and our understanding thereof in soil ecosystems. At this stage, we call upon

9 researchers and specialized soil journals to consider the current state of data analysis, interpretation and availability to

10 improve the rigor of future studies.

- Soil complexity necessitates careful interpretation of sequencing data

- Studies often do not account for data compositionality, leading to misinterpretation

- Functions should not be inferred from phylogeny as they are rarely conserved

- We discuss complementary approaches that help to improve ecological insights

- We call for journals and authors to improve study reproducibility and data availability 


\section{Keywords}

amplicon sequencing, soil metabarcoding, soil microorganisms, soil microbial diversity, soil complexity, compositional data

\section{Introduction}

Soil is one of the most biologically diverse and heterogeneous ecosystems, presenting unique challenges to scientists in the fields of soil and microbial ecology (Bickel and Or, 2020). The critical role of microorganisms as drivers of biogeochemical processes is well-documented, and a major goal of soil ecology remains to decipher the link between the diversity of soil microbial communities, and their function in the environment (Hinsinger et al., 2009; Manzoni et al., 2012). Historically, studies of microbial communities revealed rather a narrow perspective of the diversity by targeting mainly cultivable bacteria, taxa of high abundance, or microorganisms grouped according to morphological or physiological properties (Staley and Konopka, 1985; Steen et al., 2019; Åsa Frostegård et al., 2011). The introduction of next-generation sequencing technologies such as amplicon sequencing has revolutionized our understanding of microbial diversity by enabling the investigation of community composition at a much greater phylogenetic resolution than ever before.

Amplicon sequencing (also termed metabarcoding) is based on PCR-amplification of variable regions of DNA within conserved phylogenetic or functional marker genes (Gołębiewski and Tretyn, 2019; Semenov, 2021) - see also supplementary Table S1 for examples. The accessibility of established assays, the affordability, as well as the availability of free analysis software packages have facilitated the broad use of amplicon sequencing for characterization of the microbiological diversity in environmental samples (Caporaso et al., 2012). In the field of soil science, its application has accelerated in the last decade as evidenced by the growing number of studies published in specialized soil journals (Fig. 1). The majority of these manuscripts report the analysis of soil community composition and diversity based on phylogenetic marker genes such as the $16 \mathrm{~S}$ rRNA gene for bacteria and archaea as well as internal transcribed spacer (ITS) regions for fungi. In addition, functional genes can be targeted to obtain information on the organism that may contribute to a specific environmental process (Angel et al., 2018; Séneca et al., 2020; Aigle et al., 2020).

Such work has enabled researchers to successfully investigate the composition and dynamics of soil microbial communities. Our understanding of microbial diversity has increased dramatically and the activity of microbial communities has now been widely recognized as central in the field of soil science where research questions were historically often tackled from the perspective of individual disciplines such as chemistry, physics, and biology (Baveye et al., 2018). As evident by the high number of studies being published in recent years, it is safe to say that microbial community analysis via marker-gene sequencing has become a standard tool in soil research. At this stage, it is necessary to discuss potentials, challenges, and pitfalls of the technique applied by soil scientists.

In this perspective, we aim to describe the unique challenges of studying microbial communities in soil ecosystems, and to address common misconceptions in the analysis and interpretation of amplicon sequencing data. Patterns often arise in community data, but the interpretation of these patterns in a soil context remains challenging and limited due to the poor link between the sequenced marker gene 
regions and microbial functions, as well as the compositional nature of the data itself (Blanchet et al., 2020). We provide suggestions for designing sequencing experiments and analyzing data to gain improved insights into microbial community structure and dynamics within the context of the complex soil environment. Amplicon sequencing, when used as part of a well-designed experiment, represents an informative approach for investigating microbial community structure and correlations between taxa and environmental parameters, as well as for developing new hypotheses regarding microbial community dynamics.

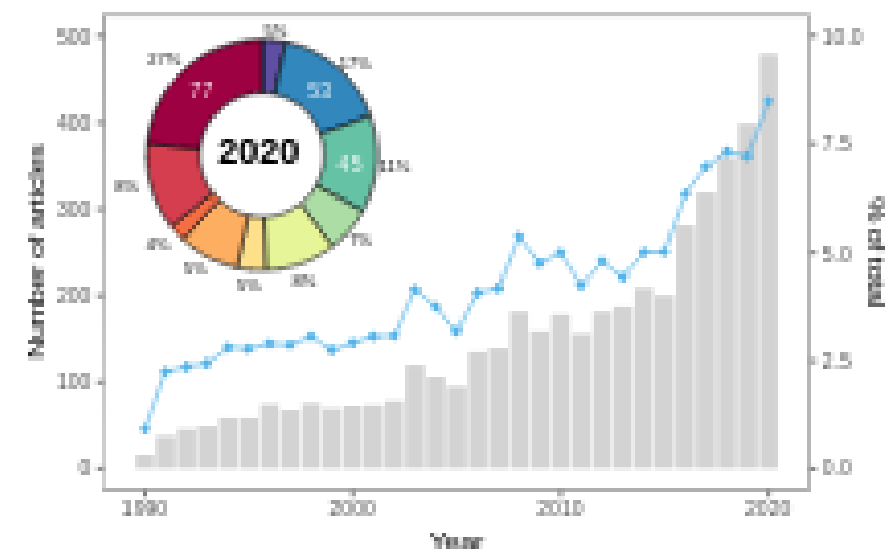

\section{Top 10 contributing} |aurnals In soll salende In 2020

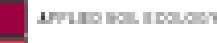
stime

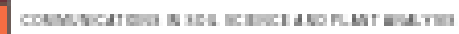

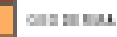

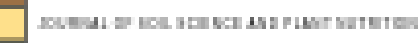

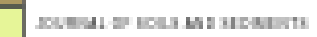

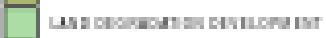

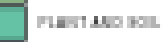

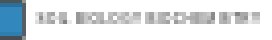

Figure 1: Increase in the number of articles using amplicon sequencing in soil microbiome research published in soil science journals (as defined in Web of Science, www.webofknowledge.com). Bars represent the total number of articles using amplicon sequencing, whereas the blue points and line represent their percentage of the total number of articles published in those journals per year from 1990 to 2020. The pie chart represents the number of articles in the top ten contributing soil science journals in 2020 (as total number of articles). Numbers inside the chart represent the number of articles using amplicon sequencing (only reported for the top three journals), while the numbers outside the chart represent the percentage of the total number of articles for each journal. See Supplementary file for a more detailed description of methods and the complete list of journals (Table S2).

\section{Technical considerations in a heterogeneous and diverse habitat}

The diversity of microorganisms in soil has been well-documented as a major challenge in studying soil microbial communities (Gans, 2005; Fierer and Jackson, 2006). A single gram of soil is estimated to contain $10^{8}-10^{9}$ cells (Bloem et al., 1995; Nunan et al., 2001) and tens of thousands of microbial taxa (Roesch et al., 2007). Additionally, compared to host-associated microbiomes (e.g., gut, skin, or plant root microbiome), free-living bacteria exhibit higher levels of diversity. In a recent comparison of alpha-, beta- and gamma-diversity from samples collected as part of the Earth Microbiome Project 
(EMP), soils were determined to have the highest alpha-diversity across all environments (Walters and Martiny, 2020). In terms of beta- and gamma-diversity, soil came in second only to sediment samples. Fewer studies have investigated the diversity and global distribution of fungi (Tedersoo et al., 2014; Větrovský et al., 2019). These studies indicate that more heterogeneous environments, such as soils and sediments, may contain more diverse fungal communities that more homogeneous habitats (e.g., marine, freshwater, air, biofilms) (Fierer and Lennon, 2011; Walters and Martiny, 2020; Torsvik, 2002).

In addition to high biological diversity, researchers interested in the microbial composition of soils are confronted with technical challenges throughout the sample processing workflow. The general workflow of amplicon sequencing includes: 1) planning and implementation of the experimental design, 2) nucleic acid extraction (influcing quality control) 3) primer choice, PCR amplification, sequencing, 4) processing and analysis of sequence data, and 5) data interpretation (Fig. 2). At each of these steps, a subset of the sample is selected and information can be lost as a result of the techniques applied (i.e., nucleic acid extraction method, primer selection, statistical approaches), with consequences for data interpretation in the context of ecological questions (Morton et al., 2019; McLaren et al., 2019). As with any scientific experiment, the specific hypotheses to be addressed should determine the experimental design. Besides this, in experiments involving amplicon sequencing, one must consider the appropriate spatial scale (i.e., aggregate/microscale, centimetre scale, meter scale) and the frequency of sampling in order to address specific questions regarding community dynamics. While the sample that is sequenced represents the specific moment in time when it was frozen or extracted, the presence of exogenous or relic DNA in soil samples has the potential to influence community composition and downstream data interpretation ((Lennon et al., 2018; Carini et al., 2016); discussed in section 5). Additionally, sample replication remains a critical concern in soil studies, particularly when it comes to statistical inference and/or construction of co-occurrence networks (discussed in sections 5 and 6).

The physicochemical properties of soils make nucleic acid extraction from this matrix particularly challenging. Numerous extraction protocols and kits have been developed to circumvent challenges with DNA extraction from soil, however, each method introduces distinct bias on the subset of the microbial community retrieved (Terrat et al., 2011; Zielińska et al., 2017; Dopheide et al., 2018). The presence of inhibitors, such as humic substances, is common in soil and can reduce the quality and purity of nucleic acids in the extracted samples and decrease the efficiency of reverse transcription and/or PCR reactions (Schrader et al., 2012). In addition to the nucleic acid extraction method of choice (chemical or physical lysis, DNA and/or RNA extraction), primer selection dictates the organisms or functions targeted by the approach (phylogenetic or functional marker; see Table S1). Finally, due to the diversity and heterogeneity of soil samples the resulting data is often sparse, containing numerous taxa with low abundance and prevalence which may be dealt with through filtering thresholds or statistical approaches (see section 3). The loss of information at each step of the process - from sampling to analysis - must be carefully considered in light of amplicon sequencing data interpretation. Keeping all these factors in mind, the application of sequencing technologies to soil has provided invaluable information regarding the structure and critical nature of understanding microbial communities. 


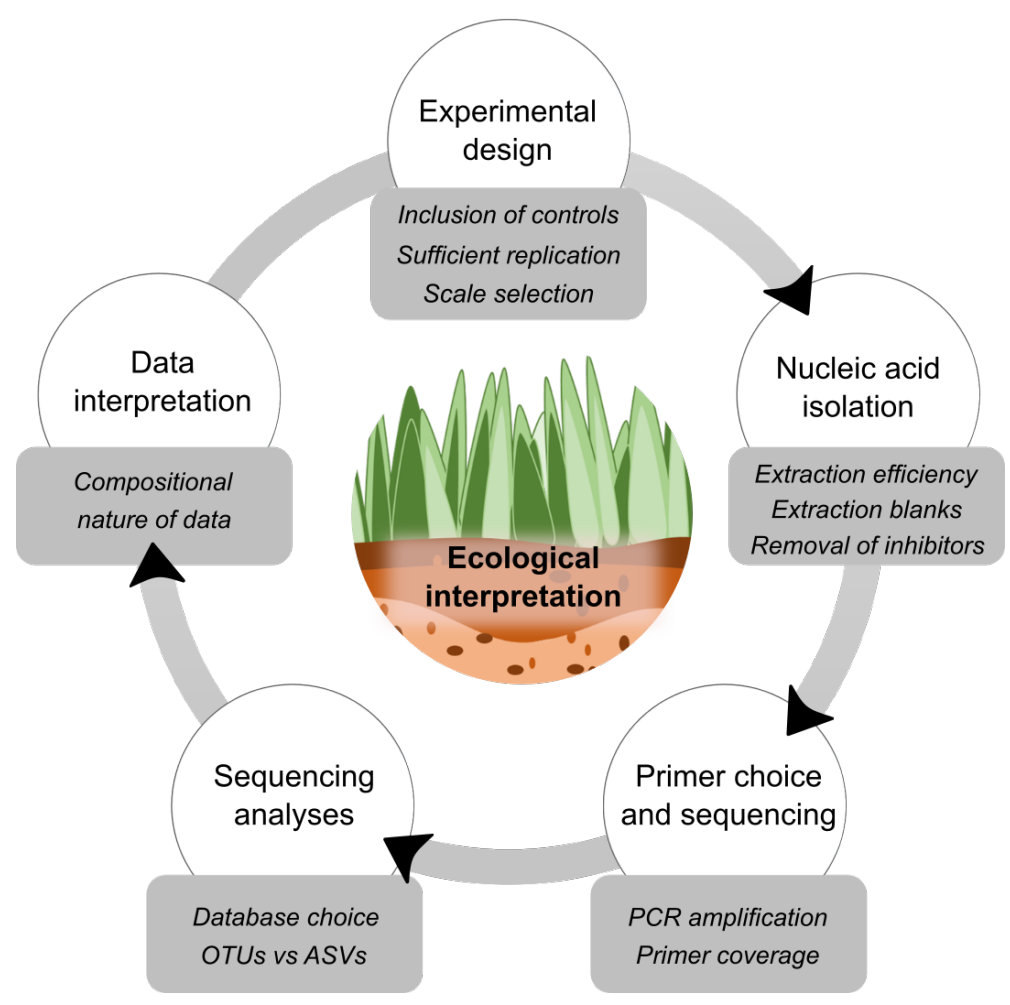

Figure 2: The main steps of an amplicon sequencing analysis workflow. Italicized items represent critical points that may strongly influence the robustness and direction of the results.

\section{Challenges in amplicon sequence data analysis}

\subsection{Primer selection dictates phylogenetic coverage}

As choice of primers can influence the taxa observed in an amplicon sequencing dataset, it is of utmost importance to take care with regard to primer selection and the interpretation of resulting data as to the community changes/impacts of treatments. Given the high diversity of soil communities (of which the understanding is constantly growing due to massive sequencing efforts), no primer pair will cover the complete phylogenetic breadth on a high rank such as domain (e.g., bacteria, archaea, fungi). As a concern when studies attribute soil functions to taxa found to be "rare" in their amplicon sequencing data due to low coverage of that group (Chen et al., 2020). Nevertheless, evaluated and recommended primer pairs are available including the updated versions of 515F-806R primers for surveys of archaea and bacteria (e.g., https://earthmicrobiome.org/). Primer selection is even more challenging for studies of eukaryotes, owing to hypervariable sequence lengths and multiple gene copy numbers (due to multiple operons and/or polykaryosis) that contribute to biased amplification of some phylogenetic groups during PCR. This bias may for example lead to the under-estimation of some fungal groups, having a downstream effect on diversity estimates (Baldrian et al., 2021). Arbuscular mycorrhizal fungi for instance are largely overlooked by commonly used ITS primers which could lead investigators to infer that arbuscular mycorrhizal fungi are rare (George et al., 2019). A promising alternative to ITS-targeted short-read sequencing is the use of long-read sequencing (e.g., PacBio) which enables the investigation of most fungi (including Glomeromycota) and other soil eukaryotes through covering both the full ITS 
region and part of the small subunite of the rRNA gene (Tedersoo and Anslan, 2019; Tedersoo et al., 2020). We refer readers to in-depth reviews that further discuss challenges regarding amplicon sequencing of fungi specifically, including discussion of primer selection and coverage (Nilsson et al., 2019; Baldrian et al., 2021).

The choice of primers has substantial impacts on estimates of diversity in community studies. As a consequence, we urge researchers to use tools such as TestPrime (https://www.arb-silva.de/search/ testprime/) to evaluate the current status of the coverage of their target microbial groups of interest before sequencing and to discuss this aspect in their publications. We also recommend that reviewers critically assess the coverage of the target group of organisms used in a study to improve future evaluation of sequencing-based research in soil ecology.

\subsection{Compositionality necessitates careful data processing}

One of the first steps in the analysis of amplicon sequencing data is the removal of potential sequencing errors. Doing so eliminates sequencing artefacts that may falsely boost diversity levels (Edgar et al., 2011; Haas et al., 2011). The use of amplicon sequencing variants (ASVs), instead of operational taxonomic units (OTUs) helps to overcome this issue by assigning a greater probability of a true biological sequence being more abundant than an error-containing sequence (Callahan et al., 2017). To that end, bioinformatic tools such as DADA2 (Callahan et al., 2016) and Deblur (Amir et al., 2017) attempt to use sequencing error profiles to resolve amplicon sequencing data into ASVs. An ASV is more likely to have an intrinsic biological meaning (i.e., being a true DNA sequence), as opposed to an OTU which can either be a representation of the most abundant biological sequence or a consensus sequence (of which the latter may not exist in reality). In addition, ASVs facilitate the merging of datasets, particularly when the same sequencing primer pairs are used.

Another relevant step when analyzing sequencing data is to account for the different sequencing efforts across samples (i.e., sequencing depth) that can result in a substantially different number of recovered reads even among replicates. Ways to tackle this include total library size normalization and rarefaction, with both remaining debated to date (McMurdie and Holmes, 2014; Weiss et al., 2017). Bioinformatic tools such as DeSeq2 and EdgeR provide ways to normalize count tables (Love et al., 2014; Robinson and Oshlack, 2010). Both methods are applied on raw or low-abundance filtered count tables, and have performed well in both real as well as simulated datasets and outperform rarefaction-based approaches (McMurdie and Holmes, 2014). Other alternatives that account for the compositional aspect of sequencing data include centered log-ratio (CLR), isometric log-ratio (ILR) or additive log-ratio (ALR) ratios transformations on a count data matrix with adequate replacements of zeros (Aitchison, 1984; Egozcue, 2003).

Following data normalization, traditional workflows include the generation of distance matrices for ordination, clustering, and variance partitioning analyses. Commonly used distance metrics include BrayCurtis, Jaccard and Unifrac (weighted and unweighted). These metrics are often used although they do not take into account the compositional nature of sequencing data. The Aitchison distance - defined as the Euclidian distance on top of a centered log-ratio transformed count matrix - is a viable compositional alternative (Aitchison, 1984) that allows performing ordinations (e.g., PCA biplots). Additionally, the "Philr" transformation metric has been introduced as a compositional alternative to the weighted Unifrac that carries phylogenetic information (Silverman et al., 2017). Most of the above mentioned compositional options are implemented in $\mathrm{R}$ packages and include publicly available tutorials. In light 
of the challenges related to normalization and analysis of compositional data, we recommend a critical evaluation of available data analysis tools to best address the nature of each experimental setup (see also section 6).

Another aspect that prevents data analyses from being fully quantitative is the potential of multiple copies of marker genes present per organism, which may also vary across taxa. For example, the 16S rRNA gene copy number per bacterial cell can vary between 1 and 18 and can additionally show variation within different strains of the same species (Stoddard et al., 2014; Coenye and Vandamme, 2003; Lavrinienko et al., 2021). Therefore, relying solely on the number and diversity of markers such a 16S rRNA genes can lead to inaccurate estimates of the relative abundance and diversity of microbial communities. Several computational tools can correct amplicon datasets for the number of 16S rRNA gene copies based on existing genome information (e.g., PICRUSt2 (Douglas et al., 2020) and CopyRighter (Angly et al., 2014)). However, correcting for 16S rRNA gene copy numbers in sequencing surveys remains challenging, particularly for soil, as the gene copy numbers are only known for a subset of the soil microbes (Louca et al., 2018; Nunan et al., 2020). This challenge becomes even more problematic for marker genes of fungi and other eukaryotes, such as protists, as the copy number here can vary drastically between taxa (Gong et al., 2013; Gong and Marchetti, 2019). Other housekeeping genes, which occur only once in a genome, have been proposed as universal phylogenetic marker genes (such as recA (Eisen, 1995)), but their use remains limited due to lower phylogenetic resolution and limited availability in databases.

\subsection{Insufficient data availability contributes to a lack of reproducibility}

Reproducibility and reusability of research results are predicated on sharing data and analysis scripts, a topic of growing relevance in light of increasing amounts of sequencing data obtained from soils around the globe and with the increasing complexity of analyses. Proper data sharing practices allow researchers to re-analyze specific aspects of published datasets, and/or investigate patterns in soil communities across datasets in the form of meta-analyses. A prerequisite to ensure data storage and availability in a usable format is that authors are required to do so by respective journals. In order to assess the current state of data deposition in the field, we searched the author guidelines of the 10 specialized soil journals (see Fig. 1 for reference). Out of the 10 journals, many "encourage their authors to make data available" while only 2 journals specifically require sequencing data to be deposited in public repositories such as GenBank before a manuscript is accepted for publication. Even if authors feel encouraged to comply, storage of their data in a repository does not always facilitate reproducibility of the reported research. Deposited datasets often contain only raw results from whole sequencing runs, and provide little meaningful information on the individual amplicons and on the corresponding metadata. As a consequence, it may be difficult to reconstitute the exact datasets used for the reported statistics and illustrations from such data. This requires that the applied quality filters and processing steps (see section 3.1), as well as the versions of applied software packages, be precisely reported.

Consequently, we call on all specialized soil journals that accept and publish sequencing data to (i) provide community standards for reproducible data analysis in their data policy statements and (ii) require the submission of sequencing data, ASV/OTU tables, together with sample metadata, to open repositories (such as GenBank, Dryad, or FigShare) and (iii) require that analysis scripts be made available on open hosting services (such as GitHub) or accompany the publication as a supplement. These steps will greatly facilitate reproducibility, open science, and meta-analyses. 


\section{Addressing and interpreting compositional sequencing data}

\subsection{Interpreting relative abundance data}

The compositionality of amplicon sequencing data presents challenges to the interpretation of changes in microbial community structure. The amount of sequence data obtained through high-throughput sequencing is a fixed value, resulting in a random sampling of sequences from a sample that cannot be directly linked to absolute abundance based on sequences alone (Gloor et al., 2017). Numerous studies have revealed shifts in microbial community composition across treatments including gradients of temperature, $\mathrm{pH}$, and salinity, as well as seasonal or temporal parameters. This practice is robust on a community level when broad-scale changes in taxa are of interest (e.g., phylum level), and has resulted in similar ecological conclusions as data generated with more quantitative approaches (Piwosz et al., 2020). However, at higher taxonomic resolution (e.g., genus level), quantitative inferences from relative abundance sequencing data become more challenging. Due to the nature of sequencing, a change in the relative abundance of one species is always reflected in a corresponding change in one or more other species. We depict such challenges in interpretation in the following thought experiment (Fig. 3).

Amplicon sequencing data obtained from the same soil sample at two different time points (t1, t2) consists of two species (A, B). The relative abundance observed for species A and B is 0.55 and 0.45 at time point 1 (t1), and 0.8 and 0.2 at time point 2 (t2), respectively (Fig. 3). From t1 to t2, species B decreases in relative abundance coupled to an increase in the relative abundance of species A. The bars below (t2a-t2e) illustrate five examples of changes in absolute abundance in t 2 that could underlie the patterns observed in relative abundance data. The initial time point (t1) is also shown for comparison.

The first case represents a situation where the absolute abundance matches the relative abundance observations. There are no changes in total biomass from t1 to t2 and species A increases, whereas species B decreases (Fig. 3, t2a). The second case depicts an increase in overall biomass between t1 and $\mathrm{t} 2$ caused by an absolute increase in species A and no absolute changes in species B (Fig. 3, t2b). The third case represents an opposite scenario where the decreases in total biomass between t1 to t2 is caused by a decrease in species B and no changes in species A (Fig. 3, t2c). The fourth case represents a situation where there is a general increase in biomass from t1 to t2 prompted by increases in absolute abundances of both species A and B (Fig. 3, t2d), while the fifth case represents an opposite scenario (Fig. 3, t2e). For some of these examples, observed changes in relative abundance may accurately reflect true biological changes ( $2 \mathrm{a}, \mathrm{t} 2 \mathrm{~d}$ and $\mathrm{t} 2 \mathrm{e}$ ), whereas interpretation of the community shifts that underlie observed patterns remains more difficult for the other scenarios ( $t 2 b$ and $t 2 c)$. Without information on absolute abundances, there is still room for ambiguous interpretations solely based on relative abundance plots (see section 4.2). This theoretical exercise shows, that even for a community of only two member species, there are five potential scenarios of changes in the absolute abundance that could cause the observed shift in relative abundance. Given that soil communities usually harbour thousands of species, the degree of complexity increases dramatically.

\subsection{Experimental approaches to address compositionality}

The challenge of interpreting relative abundance data as illustrated in Figure 3 indicates the advantages of adding quantitative information to current amplicon sequencing approaches. Knowledge on absolute values (e.g., total microbial biomass) can help to make more robust inferences about the nature of 


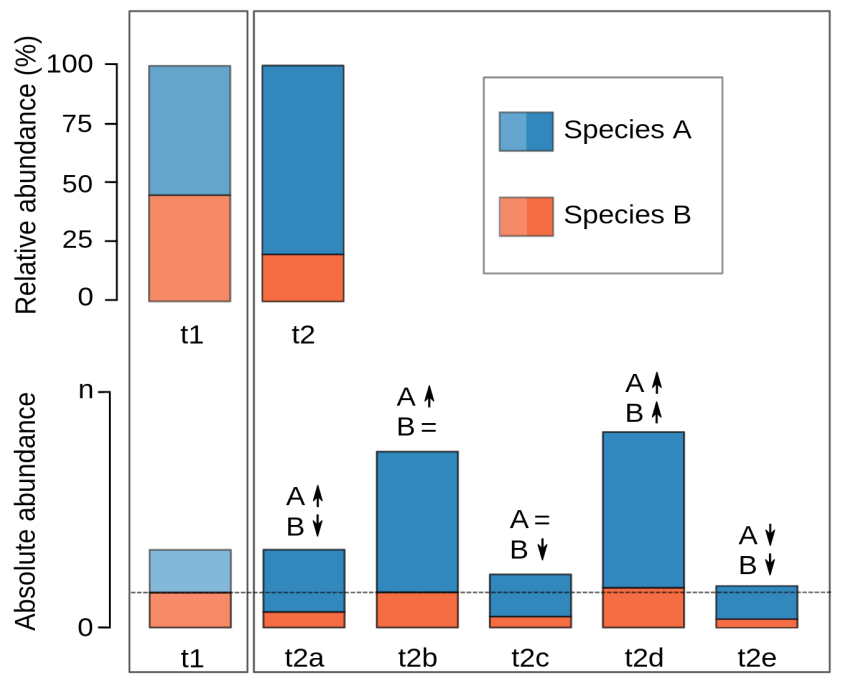

Figure 3: Relationship between the relative abundance of species as observed via amplicon sequencing and their absolute abundances. The upper panel shows the relative abundance of two species A (shades of blue) and B (shades of pink) at two time points in a theoretical experiment. From t1 to t2, a decrease in relative abundance of species B is observed, coupled to an increase in relative abundance of species A. The relative abundance pattern observed at $\mathrm{t} 2$ could have been caused by five changes in the biomass and absolute abundance of the microbial community as shown in the lower panel. Time point t1 is shown for comparison.

observed shifts in microbial community structure (Fig. 3, t2d and t2e; (Barlow et al., 2020; Wang et al., 2021). In the following, we discuss some approaches ranging from molecular techniques to classic soil microbiology that could help improve our interpretation of amplicon sequencing data.

\subsubsection{Quantitative PCR approaches}

One relatively affordable and well-established quantitative method is quantitative real-time PCR (qPCR). qPCR enables to assess copy numbers of a marker gene which may be multiplied by the relative abundance data of the same sample obtained by amplicon sequencing. This approach benefits strongly from using the same primers in both qPCR and sequencing to reduce bias stemming from PCR (see section 2) and from correcting for the copy numbers of said marker gene in the genome of target organisms.

A relatively novel alternative to traditional $\mathrm{qPCR}$ is digital PCR (dPCR) which requires no external standard for quantification, offers higher precision, and is relatively unaffected by the presence of PCR inhibitors. This represents a tremendous advantage when working with nucleic acid extracts from soil (Dong et al., 2015). However, like standard qPCR, the efficiency of this method is affected by the degeneracy of the primers, which means particular care must be taken during primer design (see section 3.1). In addition, both dPCR and qPCR are limited in terms of absolute quantification of the fungal ITS gene due to the hypervariable target region and its variable-length (Nilsson et al., 2019).

A major advantage of both quantitative PCR approaches is the possibility of using the same DNA extracts as for the community profiling without additional sample processing that would be required 
for other methods (see sections 4.2.2- 4.2.4). Consequently, quantitative PCR approaches have been used successfully to address the compositionality of sequencing data and can aid in the interpretation of microbial community data in soil (e.g., (Tkacz et al., 2018; Zemb et al., 2020; Vandeputte et al., 2017; Kleyer et al., 2017)) .

\subsubsection{Spike-ins}

Introducing an internal standard (also called a spike-in) can be a useful tool toward achieving more quantitative amplicon data analyses. Spike-ins can be introduced in the form of microbial cells (Stämmler et al., 2016) or as selected DNA sequences (Tkacz et al., 2018; Hardwick et al., 2018; Wang et al., 2021). The spike should be uniquely detectable as a non-member of the existing microbial community, and should not be introduced in concentrations that would shift the sequencing effort towards it. Additionally, the timing of the addition will determine the type of information retrieved. While adding the spike after extraction can provide good estimates of amplification and/or sequencing biases, it does not take extraction efficiency into account (Hardwick et al., 2018; Stämmler et al., 2016). A recent amplicon sequencing study applied a synthetic DNA spike of known concentration to faecal samples prior to extraction. They combined this with qPCR quantification to calculate the number of gene copies after accounting for the extraction yield. The ratio of each OTU against the initial concentration of $16 \mathrm{~S}$ rRNA genes was used to calculate more accurate abundance levels of each OTU after taking extraction efficiency into account (Zemb et al., 2020). If performed in a comparable manner, spike-ins represent a promising tool to determine abundances of taxa more quantitatively via sequencing in future soil studies.

\subsubsection{Direct cell counts}

Another approach towards absolute abundance data from soil communities are direct cell counts obtained through fluorescence microscopy (Bloem et al., 1995) or fluorescence-activated cell counting (Khalili et al., 2019; Frossard et al., 2016) of cells liberated from soil particle surfaces (Riis et al., 1998; Lentendu et al., 2013). Total counts help to assess the absolute abundance of microbial cells that fall within a certain range of parameters such as cell size and morphology. Cell counting approaches remain more straightforward for single-cell archaea and bacteria than for filamentous bacteria, fungi or other soil eukaryotes. The success of cell counting can be negatively affected by soil autofluorescence (low signalto-noise ratio), partial separation of microbial cells from soil particles, or masking the detection of cells by overlaying soil particles. Nevertheless, assessing the number of cells in samples also subjected to sequencing may help to estimate changes in absolute abundance and to better interpret sequencing data (Fig. 3).

In addition, the observation and enumeration of target species of interest through marker-based approaches (e.g., FISH: fluorescence in situ hybridization) enables the quantification of absolute abundances of those species identified through sequencing. This practice not only allows soil ecologists to verify if the change observed in relative abundance indeed translates to shifts in the community by counting taxa of interest on filters (Piwosz et al., 2020), but also expands the interpretation of sequencing data to localize and visualize species of interest in situ (e.g., on roots (Martin et al., 2020)) and to elucidate ecological implications behind changing abundances of target species in soil samples. Applications of FISH in conjunction with amplicon sequencing to soil samples are surprisingly rare albeit such targeted localization and enumeration is a powerful tool to understand the dynamics of certain phylogenetic groups in soil on a quantitative basis. 


\subsubsection{Combining classical soil biogeochemical methods with amplicon sequencing}

Traditional soil biogeochemical approaches enable the quantification of total microbial biomass in soil, including methods such as chloroform fumigation extraction (CFE)(Brookes et al., 1985), phospholipid fatty acid (PLFA) profiling (Frostegård et al., 1991; Åsa Frostegård et al., 2011; Buyer and Sasser, 2012) and ergosterol measurements (Joergensen and Wichern, 2008; Montgomery et al., 2000). In contrast to PCR-based methods, they assess the concentration of chemical microbial biomarkers in soil directly, thereby avoiding biases introduced by amplification of the target molecules. For example, such quantitative information regarding an increase or decrease in total microbial biomass between treatments would complement corresponding shifts in relative abundance data as observed via amplicon sequencing (Fig. 3). In addition to assessing total microbial biomass, PLFA measurements can also generate abundance information for microorganisms at a coarse phylogenetic resolution. The ability to obtain abundance profiles for bacteria, fungi, as well as distinguishing between gram-positive, gramnegative, and Actinobacteria, could be used as a "benchmark" for interpreting relative abundance data for more specific subsets of an amplicon dataset (i.e., (Drigo et al., 2010)). A combined interpretation of datasets from biochemical and molecular methods with fundamentally different measurement principles, however, may not always be as straightforward as the combination of amplicon sequencing data with quantitative PCR (see section 4.2.1).

Overall, we suggest that adding any quantitative measurement of microbial abundance such as quantitative PCR, cell counting, CFE, or PLFA will benefit and guide the interpretation of amplicon sequencing data. The use of more quantitative tools will provide a more robust foundation to reduce misinterpretation of compositional sequencing data by providing a link between total microbial biomass and changes in the relative abundance of microbial groups.

\section{Linking sequences to ecological context}

\subsection{Soil spatial complexity occurs on micro- and macro- scales}

Investigating microbial community composition in soils presents unique challenges. Compared to wellmixed ecosystems, microbial life (i.e., growth, activity, dormancy, and turnover) in the soil is strongly limited by the complex network of pores, as well as gas transport and diffusion in the aqueous phase (Bickel and Or, 2020; Young, 2004; Vos et al., 2013). Soil microarchitecture is a key factor that influences the potential for microorganisms to interact with each other (Wilpiszeski et al., 2019). In practice, however, the analysis of soil microbial communities through amplicon sequencing does not account for soil microarchitecture. Researchers commonly use bulk homogenization approaches to extract nucleic acids from 250 - $500 \mathrm{mg}$ of fresh soil which naturally obscures the physical structure and spatial arrangements of microbial cells in this soil sample. From the microbial perspective, nucleic acid extraction represents a macroscopic measurement of the "whole" microbial community. This practice does not negatively affect soil microbiome analyses unless interactions among microbial taxa are inferred (e.g., via network analysis, see section 5.4).

The spatial heterogeneity of soil and the microbial communities therein does not only persist on the microscale, but certainly also on a centimeter, meter, field, or ecosystem scale (Becker et al., 2006; Wolfe et al., 2006; Franklin and Mills, 2003). Sampling "the same soil" a few meters apart or at different depths 
in the soil profile might result in individual samples with varying biogeochemical properties such as $\mathrm{pH}$, water saturation, soil texture, and also plant root distribution (Zhang and Hartemink, 2021). Choosing a sufficient number of replicates to assess sample or plot variability while balancing the cost-to-gain ratio is certainly an important measure to address soil heterogeneity (see section 6). Thus, it is critical to carefully evaluate the representativeness of technical and biological replicates. A recent study showed distinct and consistent differences in bacterial and fungal communities between individual replicate soil samples throughout a season even though 10-15 cores were randomly sampled in individual subplots and pooled (Carini et al., 2020). Another study showed that chemical soil properties, as well as microbial biomass and communities, exhibited high levels of spatial variation across 49 samples in a $6 \times 6 \mathrm{~m}$ forest plot (Štursová et al., 2016). The pooling of samples, individual extractions of DNA/RNA and/or amplification reactions made from a single DNA template can certainly dampen confounding effects of community heterogeneity. Nevertheless, existing intraplot variability and representativeness of samples, as well as the appropriateness of sampling strategies to correctly address them, must be critically assessed in any study on soil microbiomes. Otherwise, drawing of generalized macroecological conclusions from soil samples taken and pooled across large distances may yield speculative information at best (Zhang et al., 2020; Dini-Andreote et al., 2020).

\subsection{Temporal scales to consider when analyzing microbial dynamics}

When designing an experiment, one must not only consider the spatial scales at which microorganisms live and interact but as well the temporal scale, i.e., the frequency at which sampling should occur to capture temporal dynamics. Amplicon sequencing represents a snapshot of microbial prevalence at a given moment. Given that microbial community turnover among different soils is may range from weeks to years (e.g., (Spohn et al., 2016)), it is difficult to assess the best temporal sampling strategy a priori. If for example effects of root exudation on soil microbial community dynamics are of interest, it is important to consider the different temporal scales of the processes to be correlated. Root exudation varies with plant development stage and shows diurnal patterns (Oburger et al., 2014), whereas community changes on a DNA level may not be detectable on such a short temporal scale (in contrast to RNA, see below). Any pattern of a single sampling time point would rather represent a legacy community that established around plant roots instead of the current state of a community that can be linked to root exudation (composition, rate) measured at the same time point.

Another soil parameter that might mask the detection of community shifts is intrinsically linked with microbial turnover: relic or environmental/exogenous DNA. Relic DNA is extracellular DNA from nonviable cells that has leaked into the environment and that is thought to persist in soils for months to years (Levy-Booth et al., 2007; Carini et al., 2016). Relic DNA has been estimated to comprise approximately $40 \%$ of the amplifiable soil DNA pool and has been successfully removed from soil samples via the application of DNAses or propidium monoazide (Lennon et al., 2018; Carini et al., 2020; Carini et al., 2016). The latter study found greater differences in soil communities across several time points where relic DNA was removed as compared to samples where relic DNA was still present. Consequently, the presence of relic DNA may complicate the interpretation of sequencing data by over- or under-estimating microbial diversity which may be of particular concern when temporal dynamics are key to the scientific question.

One possibility to address short temporal dynamics while eliminating bias of relic DNA is ribosomal RNA (rRNA) amplicon sequencing via complementary DNA (cDNA) synthesis. The lifetime of rRNA in soils 
is relatively short and has been estimated to range from days to a few weeks depending on biogeochemical parameters such as temperature, pH, and water saturation (Schostag et al., 2020; Blazewicz et al., 2013). Thus, rRNA-targeted amplicon sequencing may increase the chances of capturing dynamics within soil microbial communities over time and may be used to carefully assess the "active" fraction thereof (Vieira et al., 2019) (see Table S2). Caution should still be taken when sequencing of nucleic acids at higher frequencies, even if relic DNA has been removed or RNA is used. If community dynamics are to be investigated in short time intervals (e.g., minutes to hours) we suggest combining amplicon sequencing with methods for targeting the metabolically active cell fraction (as discussed in section 7 ).

\subsection{Inferring function from phylogeny}

Although some links exist between the environment and the community composition therein, amplicon sequencing cannot be used to predict microbial function and roles in ecological processes (Fierer et al., 2007; Fierer, 2017). Nevertheless, it can serve as a useful tool to survey microbial communities through detection of a section of a single gene or gene region (Fig. 4). The consequence of targeting a subsection of microbial genomes is that ecological insights that can be extracted from these data remain limited. Function of taxa identified via amplicon sequencing cannot simply be inferred from the phylogeny of these organisms, as complex evolutionary processes (e.g., horizontal gene transfer) play a key role in functional trait distribution across the genomes of microorganisms (Menna and Hungria, 2011). Function may not necessarily be conserved across phylogenetic levels, and therefore processes cannot be reliably predicted and assigned to taxa using amplicon sequencing targeting phylogenetic markers such as 16S rRNA genes (Nunan et al., 2020; Li et al., 2019). Consequently, we suggest to avoid inferring life strategies of taxa via their classification into a phylum (e.g., equating Proteobacteria with fast-growing r-strategist) and using such assumptions to explain processes in soils for surveys based on general markers such as $16 \mathrm{~S}$ rRNA genes (Jeewani et al., 2020) and ITS regions (Zhou et al., 2021).

Recent studies apply functional predictions using packages such as PICRUSt2 (Douglas et al., 2020) or Tax4Fun (Aßhauer et al., 2015), which suggest that metagenomes (and therefore functional potential of organisms) can be extrapolated from the sequenced amplicon using phylogenetic markers. In the case of fungi, FUNGuild or FungalTraits have been developed, which parses OTUs/ASVs into functional guilds based on similarity to existing reference sequences (Nguyen et al., 2016; Põlme et al., 2020). The main limitation of these approaches lies in the fact that they are dependent on a single gene, and the completeness of reference sequence databases, many of which remain incomplete due to bias in the types of organisms for which we have references (section 3, (Choi et al., 2016)). However, these predictionbased software packages can be used to generate valuable hypotheses for further investigation or an additional line of evidence to support a finding. In such cases, we recommend to follow up by either FISH-counting of the identified species, functional gene-targeted sequencing, or SIP experiments to learn more about the species or community that is hypothesized to be responsible/involved in an ecosystem process (further discussed in section 7).

\subsection{Interpreting co-occurrence data and networks}

Challenges associated with amplicon sequencing analysis and interpretation also complicate the use of cooccurrence network analysis from soil samples. Generally, co-occurrence analysis generates networks with biological species as nodes and edges representing associations between them. Network construction is based on the detection of significant correlations between taxa, and can be used to investigate properties 
of microbial communities including organismal co-existence (e.g., (Barberán et al., 2011)), identification of keystone species (e.g., (Banerjee et al., 2018)) and the stability of community structure (e.g., (de Vries et al., 2018; Shi et al., 2016)). There has been a recent upsurge in the number of studies including the construction of association networks for soil microbial communities. However, many of these studies have been criticized for their highly descriptive use of networks, that do not allow for an ecological interpretation of detected patterns.

The difficulty in interpretation stems from inferring causal relationships between taxa based on correlations, which is a long-standing topic of discussion in ecology (Blanchet et al., 2020; Barner et al., 2018). Particularly for soil, it is important to keep in mind that the data contained in each environmental sample is only a snapshot of complex spatio-temporal dynamics (see sections 5.1 and 5.2). As interactions occur at the level of individual microorganisms, inferring interaction among microorganisms in soil is facilitated if samples were taken on the microscale or aggregate scale, rather than on the bulk or horizon scale (see Fig. 4). Independent from scale, any sequencing data from soil capture a noisy signal which reflects several biological processes including: reproduction, death, dispersal, environmental filtering, as well as intra- and inter-specific interactions. The heterogeneity (and resulting sparsity) of amplicon datasets represents an additional confounding effect that may introduce spurious associations, posing additional challenges unique to the study of soil ecosystems.

For microbiome data, the associations are most often assigned through the detection of significant correlations between relative abundances, where spurious links can be detected if compositional data is not appropriately handled (as explained Section 4). Several popular network construction tools, including SparCC (log ratios) and SPIECEASI (clr), apply log ratios to address compositionality in the process of network construction (Kurtz et al., 2015; Friedman and Alm, 2012). Another option is to convert relative abundances into absolute values by using the total gene copy numbers obtained from qPCR (see section 4). To improve this analysis we suggest a careful comparison of data with null models to help interpret the results and eliminate some indirect associations between species (Connor et al., 2017). Additionally, the use of complementary environmental measurement data can improve ecological insights from networks (Goberna et al., 2019; Lima-Mendez et al., 2015). We recommend performing follow-up experiments to further investigate potential interactions to explore inferences made through network analysis. In summary, the field of network inference is rapidly evolving and alternatives are emerging to address currently standing issues. Nevertheless, we still lack a definite framework that allows for a straightforward interpretation of generated co-occurrence networks. 

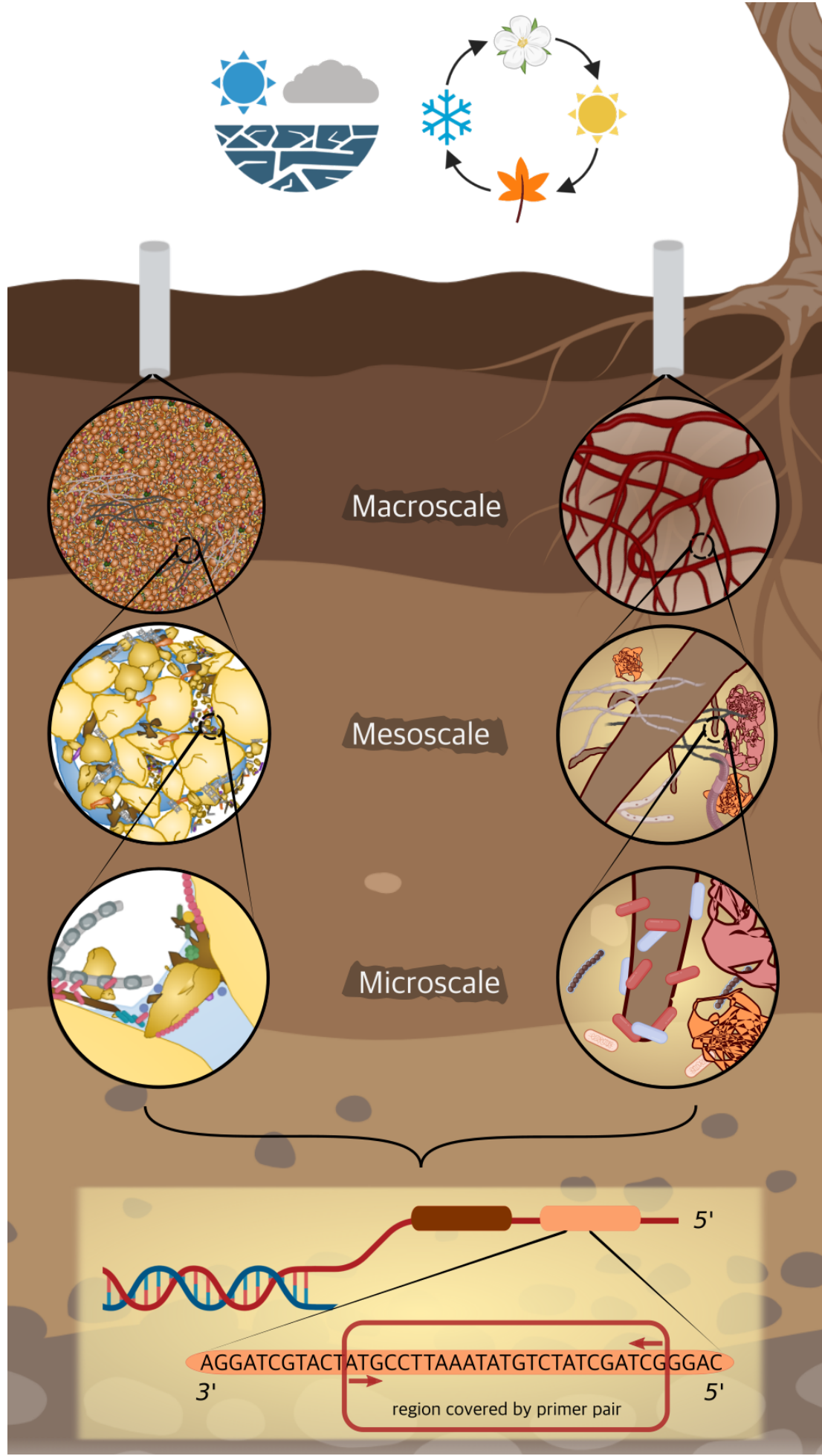

Figure 4: Schematic representation of the main spatio-temporal scales of soil ecosystems. Climate and seasonal patterns are depicted aboveground. The three main scales at which researchers investigate soil microbial communities are depicted as the macroscale, mesoscale, and microscale. Circle insets show the resolution at which microbial communities can be studied at each scale, emphasizing that careful experimental planning must be undertaken to capture community dynamics of interest. A partial single region of a selected marker gene that is captured by amplicon sequencing is depicted in the lower yellow box. 


\section{${ }_{464}$ 6. Addressing the overinterpretation of sequencing data}

Amplicon sequencing data are well-suited for exploratory analysis and hypothesis generation in soil research, but can also be applied for targeted hypothesis testing if appropriate complementary and statistical methods are selected ((Gloor et al., 2017); sections 3 and 4). As amplicon datasets from soil are characterized by compositionality, heterogeneity and sparsity, the use of standard statistical methods (including Pearson correlations or $t$-tests on proportions) can lead to very high false-positive discovery rates (up to 100\% ; (Mandal et al., 2015; Morton et al., 2017)). Almost any soil microbiome data set will show significant correlations as the data consist of thousands of individual variables. The possibility to obtain significant results, therefore, may also lead to an abuse of the statistical significance (also referred to "p hacking"). These effects are further compounded by spatio-temporal dynamics that contribute to challenges in statistical inference from amplicon sequencing in soils (see section 5). Consequently, we ask researchers to apply caution when inferring effects or associations solely based on statistical significance. The recent discussion surrounding the abuse of p-values has resulted in alternatives and suggestions for the use of more stringent p-values to reduce the false-positive discovery rate (Nuzzo, 2014; Amrhein et al., 2019; Wasserstein et al., 2019; Benjamin et al., 2017). This would require an estimated dramatic increase in sample size (up to $70 \%$ ), which would be costly, but could also save money in the long run that would have been spent on unsubstantiated research.

We explored the impact of sample replication on statistical power in soil microbiome analysis using a published dataset on bacterial and fungal communities that features a range of soils representative of the heterogeneity and biological diversity of soils (Zheng et al., 2019) (see supplementary methods) following the approach described in (Kelly et al., 2015). We simulated OTU/ASV tables (see supplementary information for description of data processing) and computed the dependency of statistical power of permutational multivariate analysis of variance (PERMANOVA) on the effect size, by bootstraping the simulated matrices with varying replicate numbers (4, 5, 8 and 10 replicates; Fig. 5). We briefly described the procedure used in the Supplementary information and address the reader to previous publication (Kelly et al., 2015) for further details and how to implement the analysis with the package 'micropower' available for $\mathrm{R}$ programming language.

Figure 5a shows the statistical power to detect significant differences with increasing effect size for multiple groups (representing different sample sizes). This clearly shows that even a small increase in the sample size increases the power to detect small differences. These results are similar to the findings described in (Kelly et al., 2015) using the Human Microbiome Project (HMP) dataset with 16S rRNA marker gene data sampled at multiple body sites. To better visualize these differences, we further calculated the average statistical power for a range of effect sizes ( $\left.\omega^{2}\right)$ defined as 'Low' (0.001-0.04), 'Medium' (0.04-0.08) and 'High' (0.08-0.12). Our analysis showed that the number of replicates hardly affects the statistical power if there was a strong effect of treatment/site(Fig. 5b, "High"). However, if the simulated treatment/site effect was lower, we found that an increase of the replicate number from 4 to 5 was sufficient to almost double the statistical power of small effect size ("Low") and to achieve the recommended power above 0.8 for medium effect sizes (Fig. 5b, "Low" and "Medium"). Consequently, these effects were more pronounced when the number of replicates was doubled (4 to 8; Fig. 5b). Identical effects were observed for the fungal data set (Fig. S1bc).

In practice, obtaining knowledge about the level of differences in soil microbial communities a priori is a complicated undertaking. If preliminary sequencing data is available we encourage researchers to perform 
such power analyses before experimental planning. Such considerations should also include the amount of technical replicates that will be pooled to alleviate the spatial heterogeneity of soils (see section 5).

We refer to further literature on experimental planning and robust statistical analyses (e.g., (Coenen et al., 2020; Kelly et al., 2015; Johnson et al., 2014)).
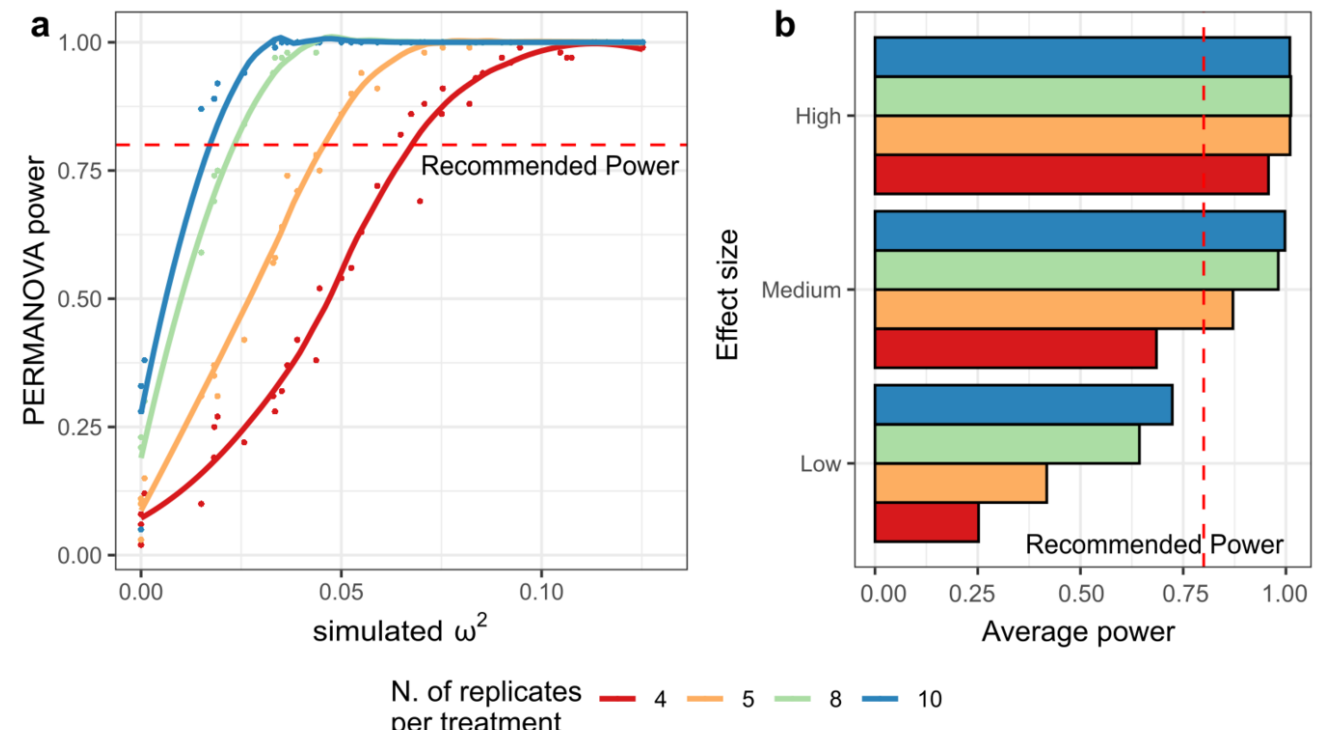

Figure 5: Graph showing: a) the calculated PERMANOVA power for a range of simulated effect (quantified by the adjusted coefficient of determination omega-squared $\left(\omega^{2}\right)$ and divided by number of replicates per treatment); b) the average PERMANOVA power of panel 'a', grouped by number of replicates per treatment and into three effect size ranges: Low (0.001-0.04), Medium (0.04-0.08) and high (0.08-0.12). PERMANOVA power was calculated as the proportion of bootstrap distance matrices for which PERMANOVA $P$-values are less than the pre-specified threshold for type I error $(0.05)$

\section{Complementary approaches to amplicon sequencing that im- prove ecological insights}

As a consequence of the relative nature of amplicon sequencing data, the majority of such studies are descriptive. Marker-gene base surveys have certainly contributed to generate valuable knowledge regarding microbial diversity and community structure, underpinning the critical roles of microorganisms in the environment. However, the limitation of using DNA sequence information to infer in situ activity, or even potential metabolic functions, has been looming over the field of environmental microbiology from its early days. This inherent property results from both the fact that two organisms with closely-related $16 \mathrm{~S}$ rRNA gene sequences might possess different metabolic capacities (Li et al., 2019), and even if the function of the organism is known, the presence of DNA or even RNA does not necessarily indicate that the cells are active (Blazewicz et al., 2013). Recent studies are beginning to combine other types of data with amplicon sequencing to improve investigations of ecological patterns.

Using stable isotopes as an indicator of activity is one of the more popular and robust ways to bridge the gap between microorganisms and their function in ecological processes. In environmental microbiology, DNA or RNA stable isotope probing (SIP) is applied by incubating a sample with a isotopically- 
labelled substrate (including heavy and rare stable isotopes of $\mathrm{C}, \mathrm{N}, \mathrm{H}$ or $\mathrm{O}$ ), that can be incorporated into the biomass of metabolically active cells (Angel, 2019; Dumont and Murrell, 2005). Unfortunately, for $\mathrm{P}$ no stable isotopes next to the one and only ${ }^{31} \mathrm{P}$ exist. The identity/community profile of the labelled organisms may then be determined using separation of different buoyant densities of the nucleic acids and subsequent sequencing of the different density fractions which allows drawing causal ecological interpretations of the microorganisms active in the uptake and/or assimilation of the substrate. Organisms labelled through SIP may further be detected and identified on a single-cell level using other methods, such as Raman microspectroscopy or NanoSIMS in combination with FISH (Musat et al., 2016; Wang et al., 2016).

Other recent advances in linking microorganisms to functions include so-called 'next-generation physiology' approaches (Hatzenpichler et al., 2020). Similar to SIP, these methods require the introduction of isotopically labelled or non-canonical molecule into the sample for the detection of metabolically active organisms. The use of heavy-water labelling has become a recent popular approach for universal targeting of all active organisms using either ${ }^{18} \mathrm{O}-\mathrm{H}_{2} \mathrm{O}$ (Aanderud and Lennon, 2011; Schwartz, 2007; Angel and Conrad, 2013) or deuterium oxide $\left(\mathrm{D}_{2} \mathrm{O}\right)$ (Li et al., 2019; Eichorst et al., 2015). The assimilation of ${ }^{18} \mathrm{O}-\mathrm{H}_{2} \mathrm{O}$ into DNA can be used to deduce microbial growth rates (Hungate et al., 2015), whereas heavy water $\left(\mathrm{D}_{2} \mathrm{O}\right)$ can be detected in the newly synthesized lipids or proteins of active cells ( $\mathrm{Li}$ et al., 2019). Combined with the identification of taxa of interest through amplicon sequencing, next-generation physiology approaches represent powerful tools to bring us to the next step in soil ecological research.

Amplicon sequencing may also be combined with with BioOrthogonal Non-Canonical Amino acid Tagging (BONCAT) to target only the fraction of cells within a soil sample that is translationally active in situ (Couradeau et al., 2019; Reichart et al., 2020). The use of modified indicator molecules opens new avenues for detecting metabolically active cells in the context of environmental samples, however, the application to soil remains limited to very few studies so far (Couradeau et al., 2019; Reichart et al., 2020). Coupling these labelling approaches to cell sorting via fluorescence-activated cell sorting (FACS) (Couradeau et al., 2019) or Raman-activated cell sorting (RACS) (Lee et al., 2019), provides a non-destructive alternative to NanoSIMS for identifying the metabolically active organisms, and thus allowing the labelled fraction of cells to be targeted for downstream sequencing. Additionally, combining these labelling approaches with cell sorting and sequencing may further circumvent challenges associated with exogenous DNA.

In addition, amplicon sequencing can certainly also be a valuable tool for planning of more targeted metagenomic or metatranscriptomic studies to investigate phylogenetic composition, functional potential and/or gene expression in the community context (Regalado et al., 2020). These approaches remain promising for improving the link between organisms and their ecological roles and circumvent methodological challenges introduced through amplicon sequencing, such as PCR bias. However, both sequencing and bioinformatic costs for gaining functionally relevant insights into ecosystem processes by "omics" approaches are typically orders of magnitudes higher than those needed for analyzing amplicon sequencing data. The use of a limited number of metagenomes or metatranscriptomes in complement to amplicon sequencing presents a cost-effective and informative approach for linking microbial community structure to function in the complex soil environment. 


\section{Summary and outlook}

Amplicon sequencing is and will remain a valuable approach for investigating the structure of microbial communities in soils. However, the complex nature of soils and high diversity of organisms therein necessitate careful considerations, from sampling strategies to statistical analyses, to avoid mis- or overinterpretation of the data. Amplicon sequencing as a standalone approach should primarily serve as a hypothesis-generation tool that is highly descriptive in nature, mainly allowing one to catalogue nucleic acids of organisms present in a given sample. As one key goal of soil microbial ecology is to link organisms to environmental processes, sequencing-based studies need to be complemented with other data types, in addition to appropriate normalization and statistical approaches. Understanding the nature of amplicon data and the role of sequencing as a valuable tool for soil scientists will further expand our understanding of microbial community diversity and structure in the immensely complex soil environment.

\section{Declaration of competing interests}

The authors declare no conflict of interest.

\section{Acknowledgements}

We thank Petra Pjevac for helpful comments on the manuscript. Figures 2 and 4 were created with the help of BioRender.com. RA was supported by the Czech Science Foundation (Junior Grant No. 19-24309Y) and MEYS (EF16_013/0001782 - SoWa Ecosystems Research). JS was supported by the Austrian Science Fund (FWF) DK' program 'Microbial Nitrogen Cycling' (W1257-B20). JJ was supported by the Czech Science Foundation (21-07275S). LA, KS and CK have received funding from the European Research Council (ERC) under the European Union's Horizon 2020 research and innovation programme (grant agreement No 819446).

\section{Supplementary Material}

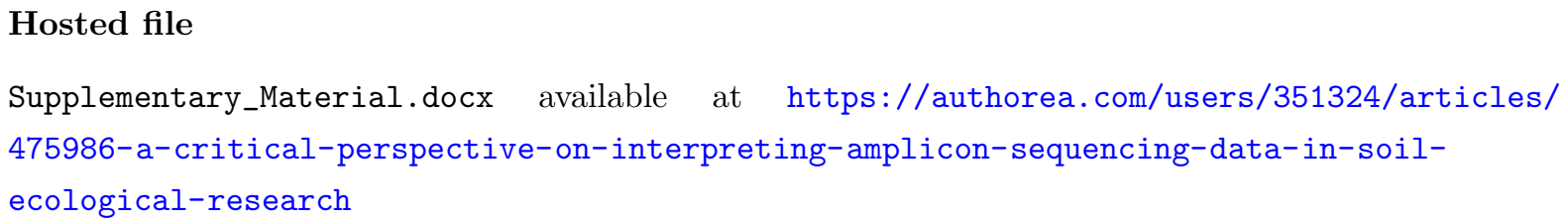

\section{References}

Aanderud, Z.T., Lennon, J.T., 2011. Validation of Heavy-Water Stable Isotope Probing for the Characterization of Rapidly Responding Soil Bacteria. Applied and Environmental Microbiology 77, 4589-4596. doi:10.1128/aem.02735-10 
Aigle, A., Gubry-Rangin, C., Thion, C., Estera-Molina, K.Y., Richmond, H., Pett-Ridge, J., Firestone, M.K., Nicol, G.W., Prosser, J.I., 2020. Experimental testing of hypotheses for temperature- and pHbased niche specialization of ammonia oxidizing archaea and bacteria. Environmental Microbiology 22, 4032-4045. doi:10.1111/1462-2920.15192

Aitchison, J., 1984. The statistical analysis of geochemical compositions. Journal of the International Association for Mathematical Geology 16, 531-564. doi:10.1007/bf01029316

Aitchison, J., 1982. The Statistical Analysis of Compositional Data. Journal of the Royal Statistical Society. Series B (Methodological) 44, 139-177.

Aitchison, J., 1986. Logratio analysis of compositions, in: The Statistical Analysis of Compositional Data. Springer Netherlands, pp. 141-183. doi:10.1007/978-94-009-4109-0

Amir, A., McDonald, D., Navas-Molina, J.A., Kopylova, E., Morton, J.T., Xu, Z.Z., Kightley, E.P., Thompson, L.R., Hyde, E.R., Gonzalez, A., Knight, R., 2017. Deblur Rapidly Resolves Single-Nucleotide Community Sequence Patterns. MSystems 2. doi:10.1128/msystems.00191-16

Amir, A., McDonald, D., Navas-Molina, J.A., Kopylova, E., Morton, J.T., Zech, X.Z., Kightley, E.P., Thompson, L.R., Hyde, E.R., Gonzalez, A., Knight, R., 2017. Deblur Rapidly Resolves Single-Nucleotide Community Sequence Patterns.. MSystems 2.

Amrhein, V., Greenland, S., McShane, B., 2019. Scientists rise up against statistical significance. Nature 567, 305-307. doi:10.1038/d41586-019-00857-9

Angel, R., 2019. Experimental Setup and Data Analysis Considerations for DNA- and RNA-SIP Experiments in the Omics Era, in: Methods in Molecular Biology. Springer New York, pp. 1-15. doi:10.1007/978-1-4939-9721-31

Angel, R., Conrad, R., 2013. Elucidating the microbial resuscitation cascade in biological soil crusts following a simulated rain event. Environmental Microbiology. doi:10.1111/1462-2920.12140

Angel, R., Nepel, M., Panhölzl, C., Schmidt, H., Herbold, C.W., Eichorst, S.A., Woebken, D., 2018. Evaluation of Primers Targeting the Diazotroph Functional Gene and Development of NifMAP - A Bioinformatics Pipeline for Analyzing nifH Amplicon Data. Frontiers in Microbiology 9. doi:10.3389/fmicb.2018.00703

Angly, F.E., Dennis, P.G., Skarshewski, A., Vanwonterghem, I., Hugenholtz, P., Tyson, G.W., 2014. CopyRighter: a rapid tool for improving the accuracy of microbial community profiles through lineagespecific gene copy number correction. Microbiome 2. doi:10.1186/2049-2618-2-11

Aßhauer, K.P., Wemheuer, B., Daniel, R., Meinicke, P., 2015. Tax4Fun: predicting functional profiles from metagenomic 16S rRNA data. Bioinformatics 31, 2882-2884. doi:10.1093/bioinformatics/btv287

Baldrian, P., Větrovský, T., Lepinay, C., Kohout, P., 2021. High-throughput sequencing view on the magnitude of global fungal diversity. Fungal Diversity. doi:10.1007/s13225-021-00472-y

Banerjee, S., Schlaeppi, K., van, der H.M.G.A., 2018. Keystone taxa as drivers of microbiome structure and functioning. Nature Reviews Microbiology 16, 567-576.

Bar-On, Y.M., Phillips, R., Milo, R., 2018. The biomass distribution on Earth. Proceedings of the National Academy of Sciences 115, 6506-6511. doi:10.1073/pnas.1711842115 
Barberán, A., Bates, S.T., Casamayor, E.O., Fierer, N., 2011. Using network analysis to explore co-occurrence patterns in soil microbial communities. The ISME Journal 6, 343-351. doi:10.1038/ismej.2011.119

Barlow, J.T., Bogatyrev, S.R., Ismagilov, R.F., 2020. A quantitative sequencing framework for absolute abundance measurements of mucosal and lumenal microbial communities. Nature Communications 11. doi:10.1038/s41467-020-16224-6

Barner, A.K., Coblentz, K.E., Hacker, S.D., Menge, B.A., 2018. Fundamental contradictions among observational and experimental estimates of non-trophic species interactions. Ecology 99, 557-566. doi:10.1002/ecy.2133

Barnett, S.E., Youngblut, N.D., Buckley, D.H., 2019. Data Analysis for DNA Stable Isotope Probing Experiments Using Multiple Window High-Resolution SIP.. Methods Mol Biol 2046, 109-128.

Baveye, P.C., Otten, W., Kravchenko, A., Balseiro-Romero, M., Éléonore Beckers, Chalhoub, M., Darnault, C., Eickhorst, T., Garnier, P., Hapca, S., Kiranyaz, S., Monga, O., Mueller, C.W., Nunan, N., Pot, V., Schlüter, S., Schmidt, H., Vogel, H.-J., 2018. Emergent Properties of Microbial Activity in Heterogeneous Soil Microenvironments: Different Research Approaches Are Slowly Converging Yet Major Challenges Remain. Frontiers in Microbiology 9. doi:10.3389/fmicb.2018.01929

Becker, J.M., Parkin, T., Nakatsu, C.H., Wilbur, J.D., Konopka, A., 2006. Bacterial Activity Community Structure, and Centimeter-Scale Spatial Heterogeneity in Contaminated Soil. Microbial Ecology 51, 220-231. doi:10.1007/s00248-005-0002-9

Benjamin, D.J., Berger, J.O., Johannesson, M., Nosek, B.A., Wagenmakers, E.-J., Berk, R., Bollen, K.A., Brembs, B., Brown, L., Camerer, C., Cesarini, D., Chambers, C.D., Clyde, M., Cook, T.D., Boeck, P.D., Dienes, Z., Dreber, A., Easwaran, K., Efferson, C., Fehr, E., Fidler, F., Field, A.P., Forster, M., George, E.I., Gonzalez, R., Goodman, S., Green, E., Green, D.P., Greenwald, A.G., Hadfield, J.D., Hedges, L.V., Held, L., Ho, T.H., Hoijtink, H., Hruschka, D.J., Imai, K., Imbens, G., Ioannidis, J.P.A., Jeon, M., Jones, J.H., Kirchler, M., Laibson, D., List, J., Little, R., Lupia, A., Machery, E., Maxwell, S.E., McCarthy, M., Moore, D.A., Morgan, S.L., Munafó, M., Nakagawa, S., Nyhan, B., Parker, T.H., Pericchi, L., Perugini, M., Rouder, J., Rousseau, J., Savalei, V., Schönbrodt, F.D., Sellke, T., Sinclair, B., Tingley, D., Zandt, T.V., Vazire, S., Watts, D.J., Winship, C., Wolpert, R.L., Xie, Y., Young, C., Zinman, J., Johnson, V.E., 2017. Redefine statistical significance. Nature Human Behaviour 2, 6-10. doi:10.1038/s41562-017-0189-z

Bickel, S., Or, D., 2020. Soil bacterial diversity mediated by microscale aqueous-phase processes across biomes. Nature Communications 11, 116.

Bickel, S., Or, D., 2020. Soil bacterial diversity mediated by microscale aqueous-phase processes across biomes. Nature Communications 11, 116.

Blanchet, F.G., Cazelles, K., Gravel, D., 2020. Co-occurrence is not evidence of ecological interactions. Ecology Letters 23, 1050-1063. doi:10.1111/ele.13525

Blazewicz, S.J., Barnard, R.L., Daly, R.A., Firestone, M.K., 2013. Evaluating rRNA as an indicator of microbial activity in environmental communities: limitations and uses. The ISME Journal 7, 2061-8.

Blazewicz, S.J., Barnard, R.L., Daly, R.A., Firestone, M.K., 2013. Evaluating rRNA as an indicator of microbial activity in environmental communities: limitations and uses. The ISME Journal 7, 2061-2068. 
doi:10.1038/ismej.2013.102

Bloem, J., Veninga, M., Shepherd, J., 1995. Fully automatic determination of soil bacterium numbers, cell volumes, and frequencies of dividing cells by confocal laser scanning microscopy and image analysis. Applied and Environmental Microbiology 61, 926-36.

Boshier, F.A.T., Srinivasan, S., Lopez, A., Hoffman, N.G., Proll, S., Fredricks, D.N., Schiffer, J.T., 2020. Complementing 16S rRNA Gene Amplicon Sequencing with Total Bacterial Load To Infer Absolute Species Concentrations in the Vaginal Microbiome. MSystems 5. doi:10.1128/msystems.00777-19

Bressan, M., Gattin, I.T., Desaire, S., Castel, L., Gangneux, C., Laval, K., 2015. A rapid flow cytometry method to assess bacterial abundance in agricultural soil. Applied Soil Ecology 88, 60-68. doi:10.1016/j.apsoil.2014.12.007

Brookes, P.C., Landman, A., Pruden, G., Jenkinson, D.S., 1985. Chloroform fumigation and the release of soil nitrogen: A rapid direct extraction method to measure microbial biomass nitrogen in soil. Soil Biology and Biochemistry 17, 837-842. doi:10.1016/0038-0717(85)90144-0

Brookes, P.C., Landman, A., Pruden, G., Jenkinson, D.S., 1985. Chloroform fumigation and the release of soil nitrogen: A rapid direct extraction method to measure microbial biomass nitrogen in soil. Soil Biology and Biochemistry 17.

Buckley, D.H., Huangyutitham, V., Hsu, S.-F., Nelson, T.A., 2007. Stable Isotope Probing with 15N2 Reveals Novel Noncultivated Diazotrophs in Soil. Applied and Environmental Microbiology 73, 3196-3204. doi:10.1128/aem.02610-06

Buyer, J.S., Sasser, M., 2012. High throughput phospholipid fatty acid analysis of soils. Applied Soil Ecology 61, 127-130. doi:10.1016/j.apsoil.2012.06.005

Callahan, B.J., McMurdie, P.J., Holmes, S.P., 2017. Exact sequence variants should replace operational taxonomic units in marker-gene data analysis. The ISME Journal 11, 2639-2643. doi:10.1038/ismej.2017.119

Callahan, B.J., McMurdie, P.J., Holmes, S.P., 2017. Exact sequence variants should replace operational taxonomic units in marker-gene data analysis.. ISME J 11, 2639-2643.

Callahan, B.J., McMurdie, P.J., Rosen, M.J., Han, A.W., Johnson, A.J., Holmes, S.P., 2016. DADA2: High-resolution sample inference from Illumina amplicon data.. Nat Methods 13, 581-3.

Callahan, B.J., McMurdie, P.J., Rosen, M.J., Han, A.W., Johnson, A.J.A., Holmes, S.P., 2016. DADA2: High-resolution sample inference from Illumina amplicon data. Nature Methods 13, 581-583. doi:10.1038/nmeth.3869

Caporaso, J.G., Lauber, C.L., Walters, W.A., Berg-Lyons, D., Huntley, J., Fierer, N., Owens, S.M., Betley, J., Fraser, L., Bauer, M., Gormley, N., Gilbert, J.A., Smith, G., Knight, R., 2012. Ultrahigh-throughput microbial community analysis on the Illumina HiSeq and MiSeq platforms. The ISME Journal 6, 1621-1624. doi:10.1038/ismej.2012.8

Carini, P., Delgado-Baquerizo, M., Hinckley, E.-L.S., Holland-Moritz, H., Brewer, T.E., Rue, G., Vanderburgh, C., McKnight, D., Fierer, N., 2020. Effects of Spatial Variability and Relic DNA Removal on the Detection of Temporal Dynamics in Soil Microbial Communities. MBio 11. doi:10.1128/mbio.02776-19 
Carini, P., Delgado-Baquerizo, M., Hinckley, E.S., Holland-Moritz, H., Brewer, T.E., Rue, G., Vanderburgh, C., McKnight, D., Fierer, N., 2020. Effects of Spatial Variability and Relic DNA Removal on the Detection of Temporal Dynamics in Soil Microbial Communities.. MBio 11.

Carini, P., Marsden, P.J., Leff, J.W., Morgan, E.E., Strickland, M.S., Fierer, N., 2016. Relic DNA is abundant in soil and obscures estimates of soil microbial diversity. Nature Microbiology 2, 16242.

Carini, P., Marsden, P.J., Leff, J.W., Morgan, E.E., Strickland, M.S., Fierer, N., 2016. Relic DNA is abundant in soil and obscures estimates of soil microbial diversity. Nature Microbiology 2. doi:10.1038/nmicrobiol.2016.242

Chen, Q.-L., Ding, J., Zhu, D., Hu, H.-W., Delgado-Baquerizo, M., Ma, Y.-B., He, J.-Z., Zhu, Y.-G., 2020. Rare microbial taxa as the major drivers of ecosystem multifunctionality in long-term fertilized soils. Soil Biology and Biochemistry 141, 107686. doi:10.1016/j.soilbio.2019.107686

Choi, J., Yang, F., Stepanauskas, R., Cardenas, E., Garoutte, A., Williams, R., Flater, J., Tiedje, J.M., Hofmockel, K.S., Gelder, B., Howe, A., 2016. Strategies to improve reference databases for soil microbiomes. The ISME Journal 11, 829-834. doi:10.1038/ismej.2016.168

Coenen, A.R., Hu, S.K., Luo, E., Muratore, D., Weitz, J.S., 2020. A Primer for Microbiome Time-Series Analysis. Frontiers in Genetics 11. doi:10.3389/fgene.2020.00310

Coenye, T., Vandamme, P., 2003. Diversity and significance of Burkholderia species occupying diverse ecological niches. Environmental Microbiology 5, 719-29.

Connor, N., Barberán, A., Clauset, A., 2017. Using null models to infer microbial co-occurrence networks. PLOS ONE 12, e0176751. doi:10.1371/journal.pone.0176751

Connor, N., Barberán, A., Clauset, A., 2017. Using null models to infer microbial co-occurrence networks.. PLoS One 12, e0176751.

Conrad, R., 2005. Quantification of methanogenic pathways using stable carbon isotopic signatures: a review and a proposal. Organic Geochemistry 36, 739-752. doi:10.1016/j.orggeochem.2004.09.006

Couradeau, E., Sasse, J., Goudeau, D., Nath, N., Hazen, T.C., Bowen, B.P., Chakraborty, R., Malmstrom, R.R., Northen, T.R., 2019. Probing the active fraction of soil microbiomes using BONCAT-FACS. Nature Communications 10. doi:10.1038/s41467-019-10542-0

DeRito, C.M., Pumphrey, G.M., Madsen, E.L., 2005. Use of Field-Based Stable Isotope Probing To Identify Adapted Populations and Track Carbon Flow through a Phenol-Degrading Soil Microbial Community. Applied and Environmental Microbiology 71, 7858-7865. doi:10.1128/aem.71.12.7858-7865.2005

Delgado-Baquerizo, M., Oliverio, A.M., Brewer, T.E., Benavent-González, A., Eldridge, D.J., Bardgett, R.D., Maestre, F.T., Singh, B.K., Fierer, N., 2018. A global atlas of the dominant bacteria found in soil. Science 359, 320-325. doi:10.1126/science.aap9516

Denk, T.R.A., Mohn, J., Decock, C., Lewicka-Szczebak, D., Harris, E., Butterbach-Bahl, K., Kiese, R., Wolf, B., 2017. The nitrogen cycle: A review of isotope effects and isotope modeling approaches. Soil Biology and Biochemistry 105, 121-137. doi:10.1016/j.soilbio.2016.11.015

Ding, C., Adrian, L., Peng, Y., He, J., 2020. 16S rRNA gene-based primer pair showed high specificity and quantification accuracy in detecting freshwater Brocadiales anammox bacteria. FEMS Microbiology Ecology 96. doi:10.1093/femsec/fiaa013 
Dini-Andreote, F., Kowalchuk, G.A., Prosser, J.I., Raaijmakers, J.M., 2020. Towards meaningful scales in ecosystem microbiome research. Environmental Microbiology 23, 1-4. doi:10.1111/1462-2920.15276

Dong, L., Meng, Y., Sui, Z., Wang, J., Wu, L., Fu, B., 2015. Comparison of four digital PCR platforms for accurate quantification of DNA copy number of a certified plasmid DNA reference material. Scientific Reports 5. doi:10.1038/srep13174

Dopheide, A., Xie, D., Buckley, T.R., Drummond, A.J., Newcomb, R.D., 2018. Impacts of DNA extraction and PCR on DNA metabarcoding estimates of soil biodiversity. Methods in Ecology and Evolution 10, 120-133. doi:10.1111/2041-210x.13086

Douglas, G.M., Maffei, V.J., Zaneveld, J., Yurgel, S.N., Brown, J.R., Taylor, C.M., Huttenhower, C., Langille, M.G.I., 2019. PICRUSt2: An improved and customizable approach for metagenome inference. doi:10.1101/672295

Douglas, G.M., Maffei, V.J., Zaneveld, J.R., Yurgel, S.N., Brown, J.R., Taylor, C.M., Huttenhower, C., Langille, M.G.I., 2020. PICRUSt2 for prediction of metagenome functions. Nature Biotechnology 38, 685-688. doi:10.1038/s41587-020-0548-6

Drigo, B., Pijl, A.S., Duyts, H., Kielak, A.M., Gamper, H.A., Houtekamer, M.J., Boschker, H.T.S., Bodelier, P.L.E., Whiteley, A.S., v. Veen, J.A., Kowalchuk, G.A., 2010. Shifting carbon flow from roots into associated microbial communities in response to elevated atmospheric CO2. Proceedings of the National Academy of Sciences of the United States of America 107, 10938-10942. doi:10.1073/pnas.0912421107

Dumont, M.G., Murrell, J.C., 2005. Stable isotope probing — linking microbial identity to function. Nature Reviews Microbiology 3, 499-504. doi:10.1038/nrmicro1162

Ebentier, D.L., Hanley, K.T., Cao, Y., Badgley, B.D., Boehm, A.B., Ervin, J.S., Goodwin, K.D., Gourmelon, M., Griffith, J.F., Holden, P.A., Kelty, C.A., Lozach, S., McGee, C., Peed, L.A., Raith, M., Ryu, H., Sadowsky, M.J., Scott, E.A., Santo, D.J., Schriewer, A., Sinigalliano, C.D., Shanks, O.C., Van, D.W.L.C., Wang, D., Wuertz, S., Jay, J.A., 2013. Evaluation of the repeatability and reproducibility of a suite of qPCR-based microbial source tracking methods.. Water Res 47, 6839-48.

Edgar, R.C., Haas, B.J., Clemente, J.C., Quince, C., Knight, R., 2011. UCHIME improves sensitivity and speed of chimera detection. Bioinformatics 27, 2194-200.

Egozcue, G.M.-F.\& C.B.-V., V. Pawlowsky-Glahn, 2003. Isometric Logratio Transformations for Compositional Data Analysis. Mathematical Geology 35, 279-300. doi:10.1023/a:1023818214614

Eichorst, S.A., Strasser, F., Woyke, T., Schintlmeister, A., Wagner, M., Woebken, D., 2015. Advancements in the application of NanoSIMS and Raman microspectroscopy to investigate the activity of microbial cells in soils. FEMS Microbiology Ecology 91, fiv106. doi:10.1093/femsec/fiv106

Eisen, J.A., 1995. The RecA protein as a model molecule for molecular systematic studies of bacteria: comparison of trees of RecAs and 16S rRNAs from the same species. Journal of Molecular Evolution 41, $1105-23$.

Faust, K., Raes, J., 2012. Microbial interactions: from networks to models.. Nat Rev Microbiol 10, $538-50$

Faust, K., Raes, J., 2012. Microbial interactions: from networks to models. Nature Reviews Microbiology 10, 538-550. doi:10.1038/nrmicro2832 
Fierer, N., 2017. Embracing the unknown: disentangling the complexities of the soil microbiome. Nature Reviews Microbiology 15, 579-590. doi:10.1038/nrmicro.2017.87

Fierer, N., Bradford, M.A., Jackson, R.B., 2007. TOWARD AN ECOLOGICAL CLASSIFICATION OF SOIL BACTERIA. Ecology 88, 1354-1364. doi:10.1890/05-1839

Fierer, N., Jackson, R.B., 2006. The diversity and biogeography of soil bacterial communities. Proceedings of the National Acadamy of Sciences of the United States of America 103, 626-31.

Fierer, N., Lennon, J.T., 2011. The generation and maintenance of diversity in microbial communities. American Journal of Botany 98, 439-448. doi:10.3732/ajb.1000498

Franklin, R.B., Mills, A.L., 2003. Multi-scale variation in spatial heterogeneity for microbial community structure in an eastern Virginia agricultural field. FEMS Microbiology Ecology 44, 335-346. doi:10.1016/s0168-6496(03)00074-6

Friedman, J., Alm, E.J., 2012. Inferring correlation networks from genomic survey data. PLOS Computational Biology 8, e1002687.

Frossard, A., Hammes, F., Gessner, M.O., 2016. Flow Cytometric Assessment of Bacterial Abundance in Soils Sediments and Sludge. Frontiers in Microbiology 7. doi:10.3389/fmicb.2016.00903

Frostegård, .A., Tunlid, A., Bååth, E., 1991. Microbial biomass measured as total lipid phosphate in soils of different organic content. Journal of Microbiological Methods 14, 151-163. doi:10.1016/01677012(91)90018-1

Gans, J., 2005. Computational Improvements Reveal Great Bacterial Diversity and High Metal Toxicity in Soil. Science 309, 1387-1390. doi:10.1126/science.1112665

George, P.B.L., Creer, S., Griffiths, R.I., Emmett, B.A., Robinson, D.A., Jones, D.L., 2019. Primer and Database Choice Affect Fungal Functional but Not Biological Diversity Findings in a National Soil Survey. Frontiers in Environmental Science 7. doi:10.3389/fenvs.2019.00173

Gloor, G.B., Macklaim, J.M., Pawlowsky-Glahn, V., Egozcue, J.J., 2017. Microbiome Datasets Are Compositional: And This Is Not Optional. Frontiers in Microbiology 8. doi:10.3389/fmicb.2017.02224

Goberna, M., Montesinos-Navarro, A., Valiente-Banuet, A., Colin, Y., Gómez-Fernández, A., Donat, S., Navarro-Cano, J.A., Verdú, M., 2019. Incorporating phylogenetic metrics to microbial co-occurrence networks based on amplicon sequences to discern community assembly processes. Molecular Ecology Resources 19, 1552-1564. doi:10.1111/1755-0998.13079

Goberna, M., Montesinos-Navarro, A., Valiente-Banuet, A., Colin, Y., Gómez-Fernández, A., Donat, S., Navarro-Cano, J.A., Verdú, M., 2019. Incorporating phylogenetic metrics to microbial co-occurrence networks based on amplicon sequences to discern community assembly processes. Molecular Ecology Resources 19, 1552-1564.

Gong, J., Dong, J., Liu, X., Massana, R., 2013. Extremely High Copy Numbers and Polymorphisms of the rDNA Operon Estimated from Single Cell Analysis of Oligotrich and Peritrich Ciliates. Protist 164, 369-379. doi:10.1016/j.protis.2012.11.006

Gong, W., Marchetti, A., 2019. Estimation of 18S Gene Copy Number in Marine Eukaryotic Plankton Using a Next-Generation Sequencing Approach. Frontiers in Marine Science 6. doi:10.3389/fmars.2019.00219 
Gorka, S., Dietrich, M., Mayerhofer, W., Gabriel, R., Wiesenbauer, J., Martin, V., Zheng, Q., Imai, B., Prommer, J., Weidinger, M., Schweiger, P., Eichorst, S.A., Wagner, M., Richter, A., Schintlmeister, A., Woebken, D., Kaiser, C., 2019. Rapid Transfer of Plant Photosynthates to Soil Bacteria via Ectomycorrhizal Hyphae and Its Interaction With Nitrogen Availability. Frontiers in Microbiology 10. doi:10.3389/fmicb.2019.00168

Gołebiewski, M., Tretyn, A., 2019. Generating amplicon reads for microbial community assessment with next-generation sequencing. Journal of Applied Microbiology 128, 330-354. doi:10.1111/jam.14380

Haas, B.J., Gevers, D., Earl, A.M., Feldgarden, M., Ward, D.V., Giannoukos, G., Ciulla, D., Tabbaa, D., Highlander, S.K., Sodergren, E., Methé, B., DeSantis, T.Z., Petrosino, J.F., Knight, R., Birren, B.W., 2011. Chimeric 16S rRNA sequence formation and detection in Sanger and 454-pyrosequenced PCR amplicons. Genome Research 21, 494-504.

Hardwick, S.A., Chen, W.Y., Wong, T., Kanakamedala, B.S., Deveson, I.W., Ongley, S.E., Santini, N.S., Marcellin, E., Smith, M.A., Nielsen, L.K., Lovelock, C.E., Neilan, B.A., Mercer, T.R., 2018. Synthetic microbe communities provide internal reference standards for metagenome sequencing and analysis. Nature Communications 9, 3096.

Hatzenpichler, R., 2015. Detection of protein-synthesizing microorganisms in the environment via bioorthogonal non-canonical amino acid tagging (BONCAT) v1. doi:10.17504/protocols.io.drp55m

Hatzenpichler, R., Krukenberg, V., Spietz, R.L., Jay, Z.J., 2020. Next-generation physiology approaches to study microbiome function at single cell level. Nature Reviews Microbiology 18, 241-256. doi:10.1038/s41579-020-0323-1

Hatzenpichler, R., Orphan, V.J., 2015. Detection of Protein-Synthesizing Microorganisms in the Environment via Bioorthogonal Noncanonical Amino Acid Tagging (BONCAT), in: Springer Protocols Handbooks. Springer Berlin Heidelberg, pp. 145-157. doi:10.1007/8623 $2015_{6} 1$

Hinsinger, P., Bengough, A.G., Vetterlein, D., Young, I.M., 2009. Rhizosphere: biophysics biogeochemistry and ecological relevance. Plant and Soil 321, 117-152. doi:10.1007/s11104-008-9885-9

Ho, A., Angel, R., Veraart, A.J., Daebeler, A., Jia, Z., Kim, S.Y., Kerckhof, F.M., Boon, N., Bodelier, P.L., 2016. Biotic Interactions in Microbial Communities as Modulators of Biogeochemical Processes: Methanotrophy as a Model System.. Front Microbiol 7, 1285.

Hungate, B.A., Mau, R.L., Schwartz, E., Caporaso, J.G., Dijkstra, P., van, G.N., Koch, B.J., Liu, C.M., McHugh, T.A., Marks, J.C., Morrissey, E.M., Price, L.B., 2015. Quantitative microbial ecology through stable isotope probing. Applied and Environmental Microbiology 81, 7570-81.

Jeewani, P.H., Gunina, A., Tao, L., Zhu, Z., Kuzyakov, Y., Zwieten, L.V., Guggenberger, G., Shen, C., Yu, G., Singh, B.P., Pan, S., Luo, Y., Xu, J., 2020. Rusty sink of rhizodeposits and associated keystone microbiomes. Soil Biology and Biochemistry 147, 107840. doi:10.1016/j.soilbio.2020.107840

Jian, C., Luukkonen, P., Yki-Järvinen, H., Salonen, A., Korpela, K., 2020. Quantitative PCR provides a simple and accessible method for quantitative microbiota profiling.. PLoS One 15, e0227285.

Joergensen, R., Wichern, F., 2008. Quantitative assessment of the fungal contribution to microbial tissue in soil. Soil Biology and Biochemistry 40, 2977-2991. doi:10.1016/j.soilbio.2008.08.017

Johnson, P.C.D., Barry, S.J.E., Ferguson, H.M., Müller, P., 2014. Power analysis for generalized linear 
mixed models in ecology and evolution. Methods in Ecology and Evolution 6, 133-142. doi:10.1111/2041210x.12306

Kelly, B.J., Gross, R., Bittinger, K., Sherrill-Mix, S., Lewis, J.D., Collman, R.G., Bushman, F.D., Li, H., 2015. Power and sample-size estimation for microbiome studies using pairwise distances and PERMANOVA. Bioinformatics 31, 2461-2468. doi:10.1093/bioinformatics/btv183

Kelly, B.J., Gross, R., Bittinger, K., Sherrill-Mix, S., Lewis, J.D., Collman, R.G., Bushman, F.D., Li, H., 2015. Power and sample-size estimation for microbiome studies using pairwise distances and PERMANOVA.. Bioinformatics 31, 2461-8.

Khalili, B., Weihe, C., Kimball, S., Schmidt, K.T., Martiny, J.B.H., 2019. Optimization of a Method To Quantify Soil Bacterial Abundance by Flow Cytometry. MSphere 4. doi:10.1128/msphere.00435-19

Kleyer, H., Tecon, R., Or, D., 2017. Resolving Species Level Changes in a Representative Soil Bacterial Community Using Microfluidic Quantitative PCR. Frontiers in Microbiology 8. doi:10.3389/fmicb.2017.02017

Knief, C., Lipski, A., Dunfield, P.F., 2003. Diversity and activity of methanotrophic bacteria in different upland soils.. Appl Environ Microbiol 69, 6703-14.

Kurtz, Z.D., Müller, C.L., Miraldi, E.R., Littman, D.R., Blaser, M.J., Bonneau, R.A., 2015. Sparse and compositionally robust inference of microbial ecological networks. PLOS Computational Biology 11, e1004226.

Ladau, J., Eloe-Fadrosh, E.A., 2019. Spatial Temporal, and Phylogenetic Scales of Microbial Ecology. Trends in Microbiology 27, 662-669. doi:10.1016/j.tim.2019.03.003

Lavrinienko, A., Jernfors, T., Koskimäki, J.J., Pirttilä, A.M., Watts, P.C., 2021. Does Intraspecific Variation in rDNA Copy Number Affect Analysis of Microbial Communities?. Trends in Microbiology $29,19-27$.

Lee, K.S., Palatinszky, M., Pereira, F.C., Nguyen, J., Fernandez, V.I., Mueller, A.J., Menolascina, F., Daims, H., Berry, D., Wagner, M., Stocker, R., 2019. An automated Raman-based platform for the sorting of live cells by functional properties. Nature Microbiology 4, 1035-1048. doi:10.1038/s41564-0190394-9

Lennon, J.T., Muscarella, M.E., Placella, S.A., Lehmkuhl, B.K., 2018. How, When, and Where Relic DNA Affects Microbial Diversity. MBio 9.

Lennon, J.T., Muscarella, M.E., Placella, S.A., Lehmkuhl, B.K., 2018. How When, and Where Relic DNA Affects Microbial Diversity. MBio 9. doi:10.1128/mbio.00637-18

Lentendu, G., Hübschmann, T., Müller, S., Dunker, S., Buscot, F., Wilhelm, C., 2013. Recovery of soil unicellular eukaryotes: An efficiency and activity analysis on the single cell level. Journal of Microbiological Methods 95, 463-469. doi:10.1016/j.mimet.2013.05.006

Levy-Booth, D.J., Campbell, R.G., Gulden, R.H., Hart, M.M., Powell, J.R., Klironomos, J.N., Pauls, K.P., Swanton, C.J., Trevors, J.T., Dunfield, K.E., 2007. Cycling of extracellular DNA in the soil environment. Soil Biology and Biochemistry 39, 2977-2991. doi:10.1016/j.soilbio.2007.06.020

Li, H.-Z., Bi, Q.-fang, Yang, K., Zheng, B.-X., Pu, Q., Cui, L., 2019. D2O-Isotope-Labeling Approach 
to Probing Phosphate-Solubilizing Bacteria in Complex Soil Communities by Single-Cell Raman Spectroscopy. Analytical Chemistry 91, 2239-2246. doi:10.1021/acs.analchem.8b04820

Li, J., Mau, R.L., Dijkstra, P., Koch, B.J., Schwartz, E., Liu, X.A., Morrissey, E.M., Blazewicz, S.J., Pett-Ridge, J., Stone, B.W., Hayer, M., Hungate, B.A., 2019. Predictive genomic traits for bacterial growth in culture versus actual growth in soil. The ISME Journal 13, 2162-2172.

Lima-Mendez, G., Faust, K., Henry, N., Decelle, J., Colin, S., Carcillo, F., Chaffron, S., Ignacio-Espinosa, J.C., Roux, S., Vincent, F., Bittner, L., Darzi, Y., Wang, J., Audic, S., Berline, L., Bontempi, G., Cabello, A.M., Coppola, L., Cornejo-Castillo, F.M., d'Ovidio, F., Meester, L.D., Ferrera, I., Garet-Delmas, M.-J., Guidi, L., Lara, E., Pesant, S., Royo-Llonch, M., Salazar, G., Sanchez, P., Sebastian, M., Souffreau, C., Dimier, C., Picheral, M., Searson, S., Kandels-Lewis, S., Gorsky, G., Not, F., Ogata, H., Speich, S., Stemmann, L., Weissenbach, J., Wincker, P., Acinas, S.G., Sunagawa, S., Bork, P., Sullivan, M.B., Karsenti, E., Bowler, C., de Vargas, C., and, J.R., 2015. Determinants of community structure in the global plankton interactome. Science 348, 1262073-1262073. doi:10.1126/science.1262073

Louca, S., Doebeli, M., Parfrey, L.W., 2018. Correcting for 16S rRNA gene copy numbers in microbiome surveys remains an unsolved problem. Microbiome 6. doi:10.1186/s40168-018-0420-9

Love, M.I., Huber, W., Anders, S., 2014. Moderated estimation of fold change and dispersion for RNAseq data with DESeq2. Genome Biology 15. doi:10.1186/s13059-014-0550-8

Love, M.I., Huber, W., Anders, S., 2014. Moderated estimation of fold change and dispersion for RNAseq data with DESeq2.. Genome Biol 15, 550.

Lu, Y., 2005. In Situ Stable Isotope Probing of Methanogenic Archaea in the Rice Rhizosphere. Science 309, 1088-1090. doi:10.1126/science.1113435

Mandal, S., Treuren, W.V., White, R.A., Eggesbø, M., Knight, R., Peddada, S.D., 2015. Analysis of composition of microbiomes: a novel method for studying microbial composition. Microbial Ecology in Health \& Disease 26. doi:10.3402/mehd.v26.27663

Manzoni, S., Taylor, P., Richter, A., Porporato, A., Ågren, G.I., 2012. Environmental and stoichiometric controls on microbial carbon-use efficiency in soils. New Phytologist 196, 79-91. doi:10.1111/j.14698137.2012.04225.x

Martin, B.C., Middleton, J.A., Fraser, M.W., Marshall, I.P.G., Scholz, V.V., Hausl, B., Schmidt, H., 2020. Cutting out the middle clam: lucinid endosymbiotic bacteria are also associated with seagrass roots worldwide. The ISME Journal 14, 2901-2905. doi:10.1038/s41396-020-00771-3

McLaren, M.R., Willis, A.D., Callahan, B.J., 2019. Consistent and correctable bias in metagenomic sequencing experiments. ELife 8. doi:10.7554/elife.46923

McMurdie, P.J., Holmes, S., 2014. Waste Not Want Not: Why Rarefying Microbiome Data Is Inadmissible. PLOS Computational Biology 10, e1003531. doi:10.1371/journal.pcbi.1003531

McMurdie, P.J., Holmes, S., 2014. Waste not, want not: why rarefying microbiome data is inadmissible.. PLoS Comput Biol 10, e1003531.

McMurdie, P.J., Holmes, S., 2013. phyloseq: an R package for reproducible interactive analysis and graphics of microbiome census data.. PLoS One 8, e61217. 
Menna, P., Hungria, M., 2011. Phylogeny of nodulation and nitrogen-fixation genes in Bradyrhizobium: supporting evidence for the theory of monophyletic origin and spread and maintenance by both horizontal and vertical transfer. International Journal of Systematic and Evolutionary Microbiology 61, 3052-3067. doi:10.1099/ijs.0.028803-0

Montgomery, H.J., Monreal, C.M., Young, J.C., Seifert, K.A., 2000. Determinination of soil fungal biomass from soil ergosterol analyses. Soil Biology and Biochemistry 32, 1207-1217. doi:10.1016/s00380717(00)00037-7

Morton, J.T., Marotz, C., Washburne, A., Silverman, J., Zaramela, L.S., Edlund, A., Zengler, K., Knight, R., 2019. Establishing microbial composition measurement standards with reference frames. Nature Communications 10. doi:10.1038/s41467-019-10656-5

Morton, J.T., Sanders, J., Quinn, R.A., McDonald, D., Gonzalez, A., Vázquez-Baeza, Y., Navas-Molina, J.A., Song, S.J., Metcalf, J.L., Hyde, E.R., Lladser, M., Dorrestein, P.C., Knight, R., 2017. Balance Trees Reveal Microbial Niche Differentiation. MSystems 2. doi:10.1128/msystems.00162-16

Murase, J., Frenzel, P., 2007. A methane-driven microbial food web in a wetland rice soil. Environmental Microbiology 9, 3025-3034. doi:10.1111/j.1462-2920.2007.01414.x

Musat, N., Musat, F., Weber, P.K., Pett-Ridge, J., 2016. Tracking microbial interactions with NanoSIMS. Current Opinion in Biotechnology 41, 114-121. doi:10.1016/j.copbio.2016.06.007

Nguyen, N.H., Song, Z., Bates, S.T., Branco, S., Tedersoo, L., Menke, J., Schilling, J.S., Kennedy, P.G., 2016. FUNGuild: An open annotation tool for parsing fungal community datasets by ecological guild. Fungal Ecology 20, 241-248. doi:10.1016/j.funeco.2015.06.006

Nilsson, R.H., Anslan, S., Bahram, M., Wurzbacher, C., Baldrian, P., Tedersoo, L., 2019. Mycobiome diversity: high-throughput sequencing and identification of fungi. Nature Reviews Microbiology 17 , 95-109.

Nilsson, R.H., Anslan, S., Bahram, M., Wurzbacher, C., Baldrian, P., Tedersoo, L., 2018. Mycobiome diversity: high-throughput sequencing and identification of fungi. Nature Reviews Microbiology 17, 95-109. doi:10.1038/s41579-018-0116-y

Nunan, N., Ritz, K., Crabb, D., Harris, K., Wu, K., Crawford, J.W., Young, I.M., 2001. Quantification of the in situ distribution of soil bacteria by large-scale imaging of thin sections of undisturbed soil. FEMS Microbiology Ecology 37, 67-77. doi:10.1111/j.1574-6941.2001.tb00854.x

Nunan, N., Schmidt, H., Raynaud, X., 2020. The ecology of heterogeneity: soil bacterial communities and C dynamics. Philosophical Transactions of the Royal Society B: Biological Sciences 375, 20190249. doi:10.1098/rstb.2019.0249

Nuzzo, R., 2014. Scientific method: Statistical errors. Nature 506, 150-152. doi:10.1038/506150a

Oburger, E., Gruber, B., Schindlegger, Y., Schenkeveld, W.D.C., Hann, S., Kraemer, S.M., Wenzel, W.W., Puschenreiter, M., 2014. Root exudation of phytosiderophores from soil-grown wheat. New Phytologist 203, 1161-1174. doi:10.1111/nph.12868

Orwin, K.H., Dickie, I.A., Holdaway, R., Wood, J.R., 2018. A comparison of the ability of PLFA and 16S rRNA gene metabarcoding to resolve soil community change and predict ecosystem functions. Soil Biology and Biochemistry 117, 27-35. doi:10.1016/j.soilbio.2017.10.036 
Paul J. McMurdie, S.H., 2013. phyloseq: An R Package for Reproducible Interactive Analysis and Graphics of Microbiome Census Data. PLOS One.

Pepe-Ranney, C., Campbell, A.N., Koechli, C.N., Berthrong, S., Buckley, D.H., 2016. Unearthing the Ecology of Soil Microorganisms Using a High Resolution DNA-SIP Approach to Explore Cellulose and Xylose Metabolism in Soil.. Front Microbiol 7, 703.

Pester, M., Rattei, T., Flechl, S., Gröngröft, A., Richter, A., Overmann, J., Reinhold-Hurek, B., Loy, A., Wagner, M., 2012. amoA-based consensus phylogeny of ammonia-oxidizing archaea and deep sequencing of amoA genes from soils of four different geographic regions.. Environ Microbiol 14, 525-39.

Piwosz, K., Shabarova, T., Pernthaler, J., Posch, T., Šimek, K., Porcal, P., Salcher, M.M., 2020. Bacterial and Eukaryotic Small-Subunit Amplicon Data Do Not Provide a Quantitative Picture of Microbial Communities, but They Are Reliable in the Context of Ecological Interpretations. MSphere 5.

Pjevac, P., Schauberger, C., Poghosyan, L., Herbold, C.W., van Kessel, M.A.H.J., Daebeler, A., Steinberger, M., Jetten, M.S.M., Lücker, S., Wagner, M., Daims, H., 2017. AmoA-Targeted Polymerase Chain Reaction Primers for the Specific Detection and Quantification of Comammox Nitrospira in the Environment. Frontiers in Microbiology 8. doi:10.3389/fmicb.2017.01508

Pratscher, J., Dumont, M.G., Conrad, R., 2011. Ammonia oxidation coupled to CO2 fixation by archaea and bacteria in an agricultural soil. Proceedings of the National Academy of Sciences 108, 4170-4175. doi:10.1073/pnas.1010981108

Põlme, S., Abarenkov, K., Nilsson, R.H., Lindahl, B.D., Clemmensen, K.E., Kauserud, H., Nguyen, N., Kjøller, R., Bates, S.T., Baldrian, P., Frøslev, T.G., Adojaan, K., Vizzini, A., Suija, A., Pfister, D., Baral, H.-O., Järv, H., Madrid, H., Nordén, J., Liu, J.-K., Pawlowska, J., Põldmaa, K., Pärtel, K., Runnel, K., Hansen, K., Larsson, K.-H., Hyde, K.D., Sandoval-Denis, M., Smith, M.E., Toome-Heller, M., Wijayawardene, N.N., Menolli, N., Reynolds, N.K., Drenkhan, R., Maharachchikumbura, S.S.N., Gibertoni, T.B., Læssøe, T., Davis, W., Tokarev, Y., Corrales, A., Soares, A.M., Agan, A., Machado, A.R., Argüelles-Moyao, A., Detheridge, A., de Meiras-Ottoni, A., Verbeken, A., Dutta, A.K., Cui, B.-K., Pradeep, C.K., Marín, C., Stanton, D., Gohar, D., Wanasinghe, D.N., Otsing, E., Aslani, F., Griffith, G.W., Lumbsch, T.H., Grossart, H.-P., Masigol, H., Timling, I., Hiiesalu, I., Oja, J., Kupagme, J.Y., Geml, J., Alvarez-Manjarrez, J., Ilves, K., Loit, K., Adamson, K., Nara, K., Küngas, K., Rojas-Jimenez, K., Bitenieks, K., Irinyi, L., Nagy, L.G., Soonvald, L., Zhou, L.-W., Wagner, L., Aime, M.C., Öpik, M., Mujica, M.I., Metsoja, M., Ryberg, M., Vasar, M., Murata, M., Nelsen, M.P., Cleary, M., Samarakoon, M.C., Doilom, M., Bahram, M., Hagh-Doust, N., Dulya, O., Johnston, P., Kohout, P., Chen, Q., Tian, Q., Nandi, R., Amiri, R., Perera, R.H., dos Santos Chikowski, R., Mendes-Alvarenga, R.L., Garibay-Orijel, R., Gielen, R., Phookamsak, R., Jayawardena, R.S., Rahimlou, S., Karunarathna, S.C., Tibpromma, S., Brown, S.P., Sepp, S.-K., Mundra, S., Luo, Z.-H., Bose, T., Vahter, T., Netherway, T., Yang, T., May, T., Varga, T., Li, W., Coimbra, V.R.M., de Oliveira, V.R.T., de Lima, V.X., Mikryukov, V.S., Lu, Y., Matsuda, Y., Miyamoto, Y., Kõljalg, U., Tedersoo, L., 2020. FungalTraits: a user-friendly traits database of fungi and fungus-like stramenopiles. Fungal Diversity 105, 1-16. doi:10.1007/s13225-020-00466-2

Ramsey, P.W., Rillig, M.C., Feris, K.P., Holben, W.E., Gannon, J.E., 2006. Choice of methods for soil microbial community analysis: PLFA maximizes power compared to CLPP and PCR-based approaches. Pedobiologia 50, 275-280. doi:10.1016/j.pedobi.2006.03.003

Regalado, J., Lundberg, D.S., Deusch, O., Kersten, S., Karasov, T., Poersch, K., Shirsekar, G., Weigel, 
D., 2020. Combining whole-genome shotgun sequencing and rRNA gene amplicon analyses to improve detection of microbe-microbe interaction networks in plant leaves. The ISME Journal 14, 2116-2130. doi:10.1038/s41396-020-0665-8

Reichart, N.J., Jay, Z.J., Krukenberg, V., Parker, A.E., Spietz, R.L., Hatzenpichler, R., 2020. Activitybased cell sorting reveals responses of uncultured archaea and bacteria to substrate amendment. The ISME Journal 14, 2851-2861. doi:10.1038/s41396-020-00749-1

Reshef, D.N., Reshef, Y.A., Finucane, H.K., Grossman, S.R., McVean, G., Turnbaugh, P.J., Lander, E.S., Mitzenmacher, M., Sabeti, P.C., 2011. Detecting Novel Associations in Large Data Sets. Science 334, 1518-1524. doi:10.1126/science.1205438

Riis, V., Lorbeer, H., Babel, W., 1998. Extraction of microorganisms from soil: evaluation of the efficiency by counting methods and activity measurements. Soil Biology and Biochemistry 30, 1573-1581. doi:10.1016/s0038-0717(97)00232-0

Robinson, M.D., McCarthy, D.J., Smyth, G.K., 2010. edgeR: a Bioconductor package for differential expression analysis of digital gene expression data.. Bioinformatics 26, 139-40.

Robinson, M.D., Oshlack, A., 2010. A scaling normalization method for differential expression analysis of RNA-seq data. Genome Biology 11, R25. doi:10.1186/gb-2010-11-3-r25

Roesch, L.F., Fulthorpe, R.R., Riva, A., Casella, G., Hadwin, A.K., Kent, A.D., Daroub, S.H., Camargo, F.A., Farmerie, W.G., Triplett, E.W., 2007. Pyrosequencing enumerates and contrasts soil microbial diversity. The ISME Journal 1, 283-90.

Röttjers, L., Faust, K., 2018. From hairballs to hypotheses-biological insights from microbial networks.. FEMS Microbiol Rev 42, 761-780.

Schmidt, H., Eickhorst, T., 2013. Spatio-temporal variability of microbial abundance and community structure in the puddled layer of a paddy soil cultivated with wetland rice (Oryza sativa L.). Applied Soil Ecology 72, 93-102. doi:10.1016/j.apsoil.2013.06.002

Schostag, M.D., Albers, C.N., Jacobsen, C.S., Priemé, A., 2020. Low Turnover of Soil Bacterial rRNA at Low Temperatures. Frontiers in Microbiology 11. doi:10.3389/fmicb.2020.00962

Schrader, C., Schielke, A., Ellerbroek, L., Johne, R., 2012. PCR inhibitors - occurrence, properties and removal. Journal of Applied Microbiology 113, 1014-26.

Schwartz, E., 2007. Characterization of Growing Microorganisms in Soil by Stable Isotope Probing with H218O. Applied and Environmental Microbiology 73, 2541-2546. doi:10.1128/aem.02021-06

Schwartz, E., Hayer, M., Hungate, B.A., Koch, B.J., McHugh, T.A., Mercurio, W., Morrissey, E.M., Soldanova, K., 2016. Stable isotope probing with 18O-water to investigate microbial growth and death in environmental samples. Current Opinion in Biotechnology 41, 14-18. doi:10.1016/j.copbio.2016.03.003

Semenov, M.V., 2021. Metabarcoding and Metagenomics in Soil Ecology Research: Achievements Challenges, and Prospects. Biology Bulletin Reviews 11, 40-53. doi:10.1134/s2079086421010084

Shi, H., Shi, Q., Grodner, B., Lenz, J.S., Zipfel, W.R., Brito, I.L., Vlaminck, I.D., 2020. Highly multiplexed spatial mapping of microbial communities. Nature. doi:10.1038/s41586-020-2983-4

Shi, S., Nuccio, E.E., Shi, Z.J., He, Z., Zhou, J., Firestone, M.K., 2016. The interconnected rhizosphere: High network complexity dominates rhizosphere assemblages. Ecology Letters 19, 926-36. 
Silverman, J.D., Washburne, A.D., Mukherjee, S., David, L.A., 2017. A phylogenetic transform enhances analysis of compositional microbiota data. ELife 6. doi:10.7554/elife.21887

Silverman, J.D., Washburne, A.D., Mukherjee, S., David, L.A., 2017. A phylogenetic transform enhances analysis of compositional microbiota data.. Elife 6 .

Sinha, R., and Galeb Abu-Ali, Vogtmann, E., Fodor, A.A., Ren, B., Amir, A., Schwager, E., Crabtree, J., Ma, S., Abnet, C.C., Knight, R., White, O., Huttenhower, C., 2017. Assessment of variation in microbial community amplicon sequencing by the Microbiome Quality Control (MBQC) project consortium. Nature Biotechnology 35, 1077-1086. doi:10.1038/nbt.3981

Spohn, M., Klaus, K., Wanek, W., Richter, A., 2016. Microbial carbon use efficiency and biomass turnover times depending on soil depth - Implications for carbon cycling. Soil Biology and Biochemistry 96, 74-81. doi:10.1016/j.soilbio.2016.01.016

Staley, J.T., Konopka, A., 1985. Measurement of in situ activities of nonphotosynthetic microorganisms in aquatic and terrestrial habitats. Annual Review of Microbiology 39, 321-46.

Steen, A.D., Crits-Christoph, A., Carini, P., DeAngelis, K.M., Fierer, N., Lloyd, K.G., Thrash, J.C., 2019. High proportions of bacteria and archaea across most biomes remain uncultured. The ISME Journal 13, 3126-3130. doi:10.1038/s41396-019-0484-y

Stoddard, S.F., Smith, B.J., Hein, R., Roller, B.R.K., Schmidt, T.M., 2014. rrnDB: improved tools for interpreting rRNA gene abundance in bacteria and archaea and a new foundation for future development. Nucleic Acids Research 43, D593-D598. doi:10.1093/nar/gku1201

Stoecker, K., Dorninger, C., Daims, H., Wagner, M., 2010. Double labeling of oligonucleotide probes for fluorescence in situ hybridization (DOPE-FISH) improves signal intensity and increases rRNA accessibility.. Appl Environ Microbiol 76, 922-6.

Stämmler, F., Gläsner, J., Hiergeist, A., Holler, E., Weber, D., Oefner, P.J., Gessner, A., Spang, R., 2016. Adjusting microbiome profiles for differences in microbial load by spike-in bacteria. Microbiome 4. doi:10.1186/s40168-016-0175-0

Séneca, J., Pjevac, P., Canarini, A., Herbold, C.W., Zioutis, C., Dietrich, M., Simon, E., Prommer, J., Bahn, M., Pötsch, E.M., Wagner, M., Wanek, W., Richter, A., 2020. Composition and activity of nitrifier communities in soil are unresponsive to elevated temperature and $\mathrm{CO} 2$ but strongly affected by drought. The ISME Journal 14, 3038-3053. doi:10.1038/s41396-020-00735-7

Taylor, S.C., Nadeau, K., Abbasi, M., Lachance, C., Nguyen, M., Fenrich, J., 2019. The Ultimate qPCR Experiment: Producing Publication Quality Reproducible Data the First Time. Trends in Biotechnology 37, 761-774. doi:10.1016/j.tibtech.2018.12.002

Tedersoo, L., Anslan, S., 2019. Towards PacBio-based pan-eukaryote metabarcoding using full-length ITS sequences. Environmental Microbiology Reports 11, 659-668. doi:10.1111/1758-2229.12776

Tedersoo, L., Anslan, S., Bahram, M., Drenkhan, R., Pritsch, K., Buegger, F., Padari, A., Hagh-Doust, N., Mikryukov, V., Gohar, D., Amiri, R., Hiiesalu, I., Lutter, R., Rosenvald, R., Rähn, E., Adamson, K., Drenkhan, T., Tullus, H., Jürimaa, K., Sibul, I., Otsing, E., Põlme, S., Metslaid, M., Loit, K., Agan, A., Puusepp, R., Varik, I., Kõljalg, U., Abarenkov, K., 2020. Regional-Scale In-Depth Analysis of Soil Fungal Diversity Reveals Strong pH and Plant Species Effects in Northern Europe. Frontiers in Microbiology 11. doi:10.3389/fmicb.2020.01953 
Tedersoo, L., Bahram, M., Põlme, S., Kõljalg, U., Yorou, N.S., Wijesundera, R., Ruiz, L.V., VascoPalacios, A.M., Thu, P.Q., Suija, A., Smith, M.E., Sharp, C., Saluveer, E., Saitta, A., Rosas, M., Riit, T., Ratkowsky, D., Pritsch, K., Põldmaa, K., Piepenbring, M., Phosri, C., Peterson, M., Parts, K., Pärtel, K., Otsing, E., Nouhra, E., Njouonkou, A.L., Nilsson, R.H., Morgado, L.N., Mayor, J., May, T.W., Majuakim, L., Lodge, D.J., Lee, S.S., Larsson, K.-H., Kohout, P., Hosaka, K., Hiiesalu, I., Henkel, T.W., Harend, H., Guo, L.-dong, Greslebin, A., Grelet, G., Geml, J., Gates, G., Dunstan, W., Dunk, C., Drenkhan, R., Dearnaley, J., Kesel, A.D., Dang, T., Chen, X., Buegger, F., Brearley, F.Q., Bonito, G., Anslan, S., Abell, S., Abarenkov, K., 2014. Global diversity and geography of soil fungi. Science 346, 1256688. doi:10.1126/science. 1256688

Terrat, S., Christen, R., Dequiedt, S., Lelièvre, M., Nowak, V., Regnier, T., Bachar, D., Plassart, P., Wincker, P., Jolivet, C., Bispo, A., Lemanceau, P., Maron, P.-A., Mougel, C., Ranjard, L., 2011. Molecular biomass and MetaTaxogenomic assessment of soil microbial communities as influenced by soil DNA extraction procedure. Microbial Biotechnology 5, 135-141. doi:10.1111/j.1751-7915.2011.00307.x

Thompson, L.R., and Jon G. Sanders, McDonald, D., Amir, A., Ladau, J., Locey, K.J., Prill, R.J., Tripathi, A., Gibbons, S.M., Ackermann, G., Navas-Molina, J.A., Janssen, S., Kopylova, E., Vázquez-Baeza, Y., González, A., Morton, J.T., Mirarab, S., Xu, Z.Z., Jiang, L., Haroon, M.F., Kanbar, J., Zhu, Q., Song, S.J., Kosciolek, T., Bokulich, N.A., Lefler, J., Brislawn, C.J., Humphrey, G., Owens, S.M., HamptonMarcell, J., Berg-Lyons, D., McKenzie, V., Fierer, N., Fuhrman, J.A., Clauset, A., Stevens, R.L., Shade, A., Pollard, K.S., Goodwin, K.D., Jansson, J.K., Gilbert, J.A., Knight, R., 2017. A communal catalogue reveals Earth's multiscale microbial diversity. Nature 551, 457-463. doi:10.1038/nature24621

Tkacz, A., Hortala, M., Poole, P.S., 2018. Absolute quantitation of microbiota abundance in environmental samples. Microbiome 6. doi:10.1186/s40168-018-0491-7

Torsvik, V., 2002. Prokaryotic Diversity-Magnitude Dynamics, and Controlling Factors. Science 296, 1064-1066. doi:10.1126/science.1071698

Ushio, M., Makoto, K., Klaminder, J., Takasu, H., Nakano, S.-ichi, 2014. High-throughput sequencing shows inconsistent results with a microscope-based analysis of the soil prokaryotic community. Soil Biology and Biochemistry 76, 53-56. doi:10.1016/j.soilbio.2014.05.010

Uyaguari-Diaz, M.I., Chan, M., Chaban, B.L., Croxen, M.A., Finke, J.F., Hill, J.E., Peabody, M.A., Rossum, T.V., Suttle, C.A., Brinkman, F.S.L., Isaac-Renton, J., Prystajecky, N.A., Tang, P., 2016. A comprehensive method for amplicon-based and metagenomic characterization of viruses bacteria, and eukaryotes in freshwater samples. Microbiome 4. doi:10.1186/s40168-016-0166-1

Vandeputte, D., Kathagen, G., D'hoe, K., Vieira-Silva, S., Valles-Colomer, M., Sabino, J., Wang, J., Tito, R.Y., Commer, L.D., Darzi, Y., Vermeire, S., Falony, G., Raes, J., 2017. Quantitative microbiome profiling links gut community variation to microbial load. Nature 551, 507-511. doi:10.1038/nature24460

Vandeputte, D., Kathagen, G., D'hoe, K., Vieira-Silva, S., Valles-Colomer, M., Sabino, J., Wang, J., Tito, R.Y., De, C.L., Darzi, Y., Vermeire, S., Falony, G., Raes, J., 2017. Quantitative microbiome profiling links gut community variation to microbial load. Nature 551, 507-511.

Vieira, S., Sikorski, J., Dietz, S., Herz, K., Schrumpf, M., Bruelheide, H., Scheel, D., Friedrich, M.W., Overmann, J., 2019. Drivers of the composition of active rhizosphere bacterial communities in temperate grasslands. The ISME Journal 14, 463-475. doi:10.1038/s41396-019-0543-4 
Vos, M., Wolf, A.B., Jennings, S.J., Kowalchuk, G.A., 2013. Micro-scale determinants of bacterial diversity in soil. FEMS Microbiology Reviews 37, 936-954. doi:10.1111/1574-6976.12023

Větrovský, T., Kohout, P., Kopecký, M., Machac, A., Man, M., Bahnmann, B.D., Brabcová, V., Choi, J., Meszárošová, L., Human, Z.R., Lepinay, C., Lladó, S., López-Mondéjar, R., Martinović, T., Mašínová, T., Morais, D., Navrátilová, D., Odriozola, I., Štursová, M., Švec, K., Tláskal, V., Urbanová, M., Wan, J., Žifčáková, L., Howe, A., Ladau, J., Peay, K.G., Storch, D., Wild, J., Baldrian, P., 2019. A meta-analysis of global fungal distribution reveals climate-driven patterns. Nature Communications 10. doi:10.1038/s41467-019-13164-8

Walters, K.E., Martiny, J.B.H., 2020. Alpha- beta-, and gamma-diversity of bacteria varies across habitats. PLOS ONE 15, e0233872. doi:10.1371/journal.pone.0233872

Wang, S., Wu, Q., Han, Y., Du, R., Wang, X., Nie, Y., Du, X., Xu, Y., 2021. Gradient Internal Standard Method for Absolute Quantification of Microbial Amplicon Sequencing Data. MSystems 6. doi:10.1128/msystems.00964-20

Wang, S., Wu, Q., Han, Y., Du, R., Wang, X., Nie, Y., Du, X., Xu, Y., 2021. Gradient Internal Standard Method for Absolute Quantification of Microbial Amplicon Sequencing Data.. MSystems 6.

Wang, Y., Huang, W.E., Cui, L., Wagner, M., 2016. Single cell stable isotope probing in microbiology using Raman microspectroscopy. Current Opinion in Biotechnology 41, 34-42. doi:10.1016/j.copbio.2016.04.018

Wasserstein, R.L., Schirm, A.L., Lazar, N.A., 2019. Moving to a World Beyond "p 0.05". The American Statistician 73, 1-19. doi:10.1080/00031305.2019.1583913

Weiss, S., Van, T.W., Lozupone, C., Faust, K., Friedman, J., Deng, Y., Xia, L.C., Xu, Z.Z., Ursell, L., Alm, E.J., Birmingham, A., Cram, J.A., Fuhrman, J.A., Raes, J., Sun, F., Zhou, J., Knight, R., 2016. Correlation detection strategies in microbial data sets vary widely in sensitivity and precision.. ISME J $10,1669-81$.

Weiss, S., Xu, Z.Z., Peddada, S., Amir, A., Bittinger, K., Gonzalez, A., Lozupone, C., Zaneveld, J.R., Vázquez-Baeza, Y., Birmingham, A., Hyde, E.R., Knight, R., 2017. Normalization and microbial differential abundance strategies depend upon data characteristics. Microbiome 5. doi:10.1186/s40168-017$0237-\mathrm{y}$

Wilpiszeski, R.L., Aufrecht, J.A., Retterer, S.T., Sullivan, M.B., Graham, D.E., Pierce, E.M., Zablocki, O.D., Palumbo, A.V., Elias, D.A., 2019. Soil Aggregate Microbial Communities: Towards Understanding Microbiome Interactions at Biologically Relevant Scales. Applied and Environmental Microbiology 85. doi:10.1128/aem.00324-19

Wolfe, B.E., Mummey, D.L., Rillig, M.C., Klironomos, J.N., 2006. Small-scale spatial heterogeneity of arbuscular mycorrhizal fungal abundance and community composition in a wetland plant community. Mycorrhiza 17, 175-183. doi:10.1007/s00572-006-0089-y

Young, I.M., 2004. Interactions and Self-Organization in the Soil-Microbe Complex. Science 304, 1634-1637. doi:10.1126/science.1097394

Zemb, O., Achard, C.S., Hamelin, J., Almeida, M.-L.D., Gabinaud, B., Cauquil, L., Verschuren, L.M.G., Godon, J.-J., 2020. Absolute quantitation of microbes using 16S rRNA gene metabarcoding: A rapid 
normalization of relative abundances by quantitative PCR targeting a 16S rRNA gene spike-in standard. MicrobiologyOpen 9. doi:10.1002/mbo3.977

Zemb, O., Achard, C.S., Hamelin, J., De, A.M.L., Gabinaud, B., Cauquil, L., Verschuren, L.M.G., Godon, J.J., 2020. Absolute quantitation of microbes using 16S rRNA gene metabarcoding: A rapid normalization of relative abundances by quantitative PCR targeting a 16S rRNA gene spike-in standard. MicrobiologyOpen 9, e977.

Zhang, K., Delgado-Baquerizo, M., Zhu, Y.-G., Chu, H., 2020. Space Is More Important than Season when Shaping Soil Microbial Communities at a Large Spatial Scale. MSystems 5. doi:10.1128/msystems.00783-19

Zhang, Y., Hartemink, A.E., 2021. Quantifying short-range variation of soil texture and total carbon of a 330-ha farm. CATENA 201, 105200. doi:10.1016/j.catena.2021.105200

Zhang, Z., Qu, Y., Li, S., Feng, K., Wang, S., Cai, W., Liang, Y., Li, H., Xu, M., Yin, H., Deng, Y., 2017. Soil bacterial quantification approaches coupling with relative abundances reflecting the changes of taxa.. Sci Rep 7, 4837.

Zheng, Q., Hu, Y., Zhang, S., Noll, L., Böckle, T., Dietrich, M., Herbold, C.W., Eichorst, S.A., Woebken, D., Richter, A., Wanek, W., 2019. Soil multifunctionality is affected by the soil environment and by microbial community composition and diversity. Soil Biology and Biochemistry 136, 107521. doi:10.1016/j.soilbio.2019.107521

Zheng, Q., Hu, Y., Zhang, S., Noll, L., Böckle, T., Dietrich, M., Herbold, C.W., Eichorst, S.A., Woebken, D., Richter, A., Wanek, W., 2019. Soil multifunctionality is affected by the soil environment and by microbial community composition and diversity.. Soil Biol Biochem 136, 107521.

Zhou, J., Wen, Y., Shi, L., Marshall, M.R., Kuzyakov, Y., Blagodatskaya, E., Zang, H., 2021. Strong priming of soil organic matter induced by frequent input of labile carbon. Soil Biology and Biochemistry 152, 108069. doi:10.1016/j.soilbio.2020.108069

Zielińska, S., Radkowski, P., Blendowska, A., Ludwig-Gałezowska, A., Łoś, J.M., Łoś, M., 2017. The choice of the DNA extraction method may influence the outcome of the soil microbial community structure analysis. MicrobiologyOpen 6, e00453. doi:10.1002/mbo3.453

de Vries, F.T., Griffiths, R.I., Bailey, M., Craig, H., Girlanda, M., Gweon, H.S., Hallin, S., Kaisermann, A., Keith, A.M., Kretzschmar, M., Lemanceau, P., Lumini, E., Mason, K.E., Oliver, A., Ostle, N., Prosser, J.I., Thion, C., Thomson, B., Bardgett, R.D., 2018. Soil bacterial networks are less stable under drought than fungal networks. Nature Communications 9, 3033.

n.d.

n.d.

n.d.

n.d.

2020. . ISME Journal.

2021. . MSystems.

2021. . MSystems. 
n.d.

n.d.

1213 n.d.

1214 n.d.

1215 n.d.

Åsa Frostegård, Tunlid, A., Bååth, E., 2011. Use and misuse of PLFA measurements in soils. Soil

1217 Biology and Biochemistry 43, 1621-1625. doi:10.1016/j.soilbio.2010.11.021

1218 Štursová, M., Bárta, J., Šantrůčková, H., Baldrian, P., 2016. Small-scale spatial heterogeneity of ecosys-

1219 tem properties microbial community composition and microbial activities in a temperate mountain forest soil. FEMS Microbiology Ecology 92, fiw185. doi:10.1093/femsec/fiw185 